\title{
Adequacy of Frequency Reserves for High Wind Power Generation
}

Das, Kaushik; Litong-Palima, Marisciel; Maule, Petr; Altin, Müfit; Hansen, Anca Daniela; Sørensen, Poul Ejnar; Abildgaard, Hans

Published in:

I E T Renewable Power Generation

Link to article, DOI:

10.1049/iet-rpg.2016.0501

Publication date:

2017

Document Version

Early version, also known as pre-print

Link back to DTU Orbit

Citation (APA):

Das, K., Litong-Palima, M., Maule, P., Altin, M., Hansen, A. D., Sørensen, P. E., \& Abildgaard, H. (2017). Adequacy of Frequency Reserves for High Wind Power Generation. I E T Renewable Power Generation, 11(8), 1286-1294. https://doi.org/10.1049/iet-rpg.2016.0501

\section{General rights}

Copyright and moral rights for the publications made accessible in the public portal are retained by the authors and/or other copyright owners and it is a condition of accessing publications that users recognise and abide by the legal requirements associated with these rights.

- Users may download and print one copy of any publication from the public portal for the purpose of private study or research.

- You may not further distribute the material or use it for any profit-making activity or commercial gain

- You may freely distribute the URL identifying the publication in the public portal 
This article has been accepted for publication in a future issue of this journal, but has not been fully edited.

Content may change prior to final publication in an issue of the journal. To cite the paper please use the doi provided on the Digital Library page.

Associate Editor

Comments to Author :

(1) This paper illustrates that power forecasts for different time scales as well as available wind power in real-time are modeled for future European wind power scenarios of 2020 and 2030. The reviewer suggests that the authors provide more details on the theoretical derivation. For example, the explanation of Figs. 5 and 7 need to be improved. The reviewer also suggests the authors include more simulation results in the Section of System Studies. For example, compare the performance of the proposed technique with the existing work.

(2) Reducing the power output of wind farm will certainly decrease the economic benefit of wind farms. The corcerned discussion will be welcome.

Authors sincerely thanks the editor for the feedback. Based on the feedback following changes are made:

1) More theoretical derivations are included. Figure 5 and 7 are simplified for better understanding and explained in a lucid manner.

2) Performance of the algorithm is compared with one of the existing methodology in the literature. This existing methodology is also discussed.

3) More literature that is relevant are added. One of the existing methodology is discussed in details and performance of the algorithm is compared with this methodology.

4) This paper is concerned on volume of reserve required and not on sources of reserves. Reserves can be provided from any kind of generation sources and not necessarily wind power plants. A discussion is included in this regard in the paper.

\section{Reviewer: 1}

Comments to the Author

This paper illustrates that power forecasts for different time scales as well as available wind power in real-time are modeled for future European wind power scenarios of 2020 and 2030. The reviewer suggests that the authors provide more details on the theoretical derivation. For example, the explanation of Figs. 5 and 7 need to be improved. The reviewer also suggests the authors include more simulation results in the Section of System Studies. For example, compare the performance of the proposed technique with the existing work

Authors sincerely thanks the reviewer for the review. Based on the review following changes are made:

1) More theoretical derivations are included. Figure 5 and 7 are simplified for better understanding and explained in a lucid manner.

2) Performance of the algorithm is compared with one of the existing methodology in the literature. This existing methodology is also discussed. 
This article has been accepted for publication in a future issue of this journal, but has not been fully edited.

Content may change prior to final publication in an issue of the journal. To cite the paper please use the doi provided on the Digital Library page.

Reviewer: 2

Comments to the Author

This paper researchs the reserve capacity estimation of wind farms to handle the wind power forecast error. The paper is well written and the topic is very meaningful. However, I have the following comments that may help improve this manuscript.

1) Are there any literatures that discuss the wind power reserve capacity estimation? The reference may be more complete if the corcerned literature can be added.

2) Reducing the power output of wind farm will certainly decrease the economic benefit of wind farms. The corcerned discussion will be welcome.

Authors sincerely thanks the reviewer for the review. Based on the review following changes are made:

1) More literature that is relevant are added. One of the existing methodology is discussed in details and performance of the algorithm is compared with this methodology.

2) This paper is concerned on volume of reserve required and not on sources of reserves. Reserves can be provided from any kind of generation sources and not necessarily wind power plants. A discussion is included in this regard in the paper.

Reviewer: 3

Comments to the Author

This paper presents an application of reserve estimation on frequency restoration under the background of future wind integration in EU. However, the reviewer is not fully convinced by the academic and practical quality of the paper. The reasons are as follows:

1. The algorithm proposed in Equ(1), Fig. 6 and Fig. 7 is nothing novel. They are based on current industrial standards.

2. A setting of a cross-border AGC is quite complicated. The requirements on frequency deviation are mostly relying on the transient process of frequency restoration, such as Fig. 1 . However, the model introduced in Section II is a simulation tool to represent normal wind power fluctuation based on averaged weather forecasting. This kind of fluctuation is very hard to cause any frequency incident on an integrated power system.

3. Therefore, in real market, the major reserve is for hourly/daily power imbalance. And, yes, there is a chance of participating in secondary control. But the reserve quantity is relatively much small.

4. The simulation is also not clear enough. How is the EU power system look like? What is general capacity overview of system. Why are there differences of different countries?

Authors thanks the reviewer for the review. Based on the review following discussions are made:

1) Authors can't find any algorithm that estimates the reserve requirements for wind power forecast errors for future European power system. The aim and novelty of this methodology has been to estimate the adequacy of reserves for wind power imbalance based on TSO practice, therefore, industry standards are followed. 
This article has been accepted for publication in a future issue of this journal, but has not been fully edited.

Content may change prior to final publication in an issue of the journal. To cite the paper please use the doi provided on the Digital Library page.

2) In future European power systems with high penetration of wind power, there can be ramping of high amount of power in 10-15 minutes. For example, a storm can disconnect a large wind farm in this time. This imbalance need to be handled with operating reserves. Since, RR may be slow enough to participate in balancing, FRR needs to be activated by AGC. If FRR is not sufficient, FCR will be activated. FCR are designed to handle unforeseen contingencies and not ramping imbalances from wind power generations. Therefore, FRR should be dimensioned properly to prevent utilization of expensive FCR.

In present scenario (also in 2020 scenario as shown in the paper), this is not a problem. However, it may be a problem in 2030 scenario. Wind fluctuations may cause using up of FRR resulting in frequency incidents.

These discussions have been added in the paper.

3) Imbalance based on hourly forecast error has been studied in this paper. Yes, the reserve quantity is small in present scenario. The motivation of this paper is to assess whether this small amount of reserves will be enough for future wind power scenarios mainly for countries with high penetration of wind power generation (eg. Denmark, Germany etc.)

4) The differences in different countries are due to difference in wind power installation and loads. Figure 4 is modified to address this issue. 
This article has been accepted for publication in a future issue of this journal, but has not been fully edited.

Content may change prior to final publication in an issue of the journal. To cite the paper please use the doi provided on the Digital Library page.

\title{
Adequacy of Frequency Reserves for High Wind Power Generation
}

\author{
Kaushik Das ${ }^{1, *}$, Marisciel Litong-Palima ${ }^{1}$, Petr Maule ${ }^{1}$, Müfit Altin ${ }^{1}$, Anca D Hansen ${ }^{1}$, Poul E \\ Sørensen ${ }^{1}$, Hans Abildgaard ${ }^{2}$ \\ ${ }^{1}$ Wind Energy, Technical University of Denmark, Risø, Roskilde, 4000 Denmark \\ ${ }^{2}$ Energinet.Dk, Fredericia, Denmark \\ *kdas@dtu.dk
}

\begin{abstract}
In this article, a new methodology is developed to assess the adequacy of frequency reserves to handle power imbalances caused by wind power forecast errors. The goal of this methodology is to estimate the adequate volume and speed of activation of frequency reserves required to handle power imbalances caused due to high penetration of wind power. An algorithm is proposed and developed to estimate the power imbalances due to wind power forecast error following activation of different operating reserves. Frequency containment reserve requirements for mitigating these power imbalances are developed through this methodology. Furthermore, the probability of reducing this frequency containment reserve requirement is investigated through this methodology with activation of different volumes and speed of frequency restoration reserve. Wind power generation for 2020 and 2030 scenarios for Continental Europe network are investigated based on which recommendations are made for requirements of frequency reserves in these scenarios. It has been observed through simulations that frequency containment reserve requirements reduce exponentially with increase in volume of frequency restoration reserve and remains almost unaffected by increase activation speed of frequency restoration reserve.
\end{abstract}

\section{Introduction}

Wind energy will increasingly make larger contributions to electricity generation throughout the world. It is expected that wind energy will meet $15.7 \%$ and $28.5 \%$ of European electricity consumption in 2020 and 2030 respectively [1]. In order to operate power systems in reliable, secured manner and with stable frequency; generation should always be able to match demand in the system. There are many uncertainties in the system, namely uncertainties due to outages, load, generation, topology, weather etc. Generally, these uncertainties are handled with the help of operating reserves. However, if the reserves are not sufficient to contain the frequency change, the system is driven into emergency situation activating defence plans [2, 3, 4].

There are different nomenclatures for operating reserves. In Union for the Co-ordination of Transmission of Electricity (UCTE) operation handbook [5], different operating reserves were referred to as primary reserves, secondary reserves and tertiary reserves based on the type of control used to stabilize the frequency of the network. These reserves are referred as frequency containment reserves, frequency restoration reserves and replacement reserves based on their functionalities in current European Commission guideline on electricity transmission system operation [6]. Whereas, operating reserves are classified as automatic active reserve (Frequency controlled 
This article has been accepted for publication in a future issue of this journal, but has not been fully edited.

Content may change prior to final publication in an issue of the journal. To cite the paper please use the doi provided on the Digital Library page.

normal operation reserve and Frequency controlled disturbance reserve), fast active disturbance reserve, slow active disturbance reserve and reactive reserve in Nordic Grid Code [7]. Milligan et. al. [8] provides a comprehensive overview of different nomenclatures of operating reserves used in different regions. In this paper, the convention of frequency containment reserves (FCR), frequency restoration reserves (FRR) and replacement reserves (RR) are followed.

In the future European power systems, wind power generation will have higher contribution resulting in an increase in uncertainties in the system. The uncertainty in wind power generation mainly comes from wind power forecast error resulting in power imbalances. In general power imbalances are managed and mitigated significantly by the balance responsible parties, however, fast and short term imbalances are handled by the operating frequency reserves. The accuracy of the wind forecast improves as time horizon is closer to the operation time. Therefore, the transmission system operators(TSOs) at the control center can take better decisions to reduce the imbalance closer to the real time operation. Closer to real-time operation operators can predict imbalance prognoses with reduced forecast error based on which they can activate slow and manual RR. The remaining imbalance, if substantial, are handled by short-term FCR and FRR through primary and secondary controls respectively. These limited short-term reserves are replenished by RR. FCR and FRR are traditionally dimensioned in order to handle the imbalances caused due to any unforeseen contingency as well as to handle the market driven deterministic deviations and stochastic nature of the load. Short-term reserves specially FCR are designed to handle unforeseen contingencies and not ramping imbalances from wind power generations. Therefore, it is very important to note that the reserves utilized to meet imbalance due to wind power generation will reduce the available reserve to handle other imbalances such as contingency as per n- 1 security constraint. In past, many studies have been performed regarding requirements of operating reserves with integration of wind power generation. Ela et. al. [9] and Milligan et. al. [8] provide comprehensive review of operating reserve requirements with integration of variable generations. Ela et. al. [10] and Holttinen et. al. [11] discuss about determination of requirements of operating reserves with integration of wind power generation. Kiviluoma et. al. [12], Botterud et. al. [13], discuss impacts of wind power integration in operating reserve requirements from power system market and unit commitment point of view. Menemenlis et. al. [14] show the advantages of using dynamic operating balancing reserve at time horizon of 1-48 hours over static reserves with integration of wind power. Authors of this paper have discussed the possible challenges faced by future power systems with high wind power scenarios due to errors in wind forecast [15].

However, these methods provided in literature do not estimate the reserve requirements based on wind power time-series. As a result the ramp up and ramp down of wind power are not considered in these available methods in literature. Sorensen et. al. [16] deals with wind power fluctuations from a wind farm in the time range between one minute and up to a couple of hours. Sorensen et. al. [16, 17] and Parsons et. al. [18] provide methods for determining the need for system generation reserves due to wind power fluctuations based on the ramping characteristics of the wind farm at different power levels. However, these methods do not incorporate the decisions taken by the operators based on the prognose of wind power imbalance. In this paper, a new methodology for estimation of reserves is compared with the ramp rate based reserve estimation method from [16]. The goal of this paper is to develop a new methodology to assess the adequacy of frequency reserves to handle power imbalances caused by wind power forecast errors for power systems with high wind power penetration. This methodology estimates wind power imbalances considering activation of FRR and RR. Following which the probabilistic risk of FCR requirements exceeding the design FCR limits for mitigating these power imbalances are estimated. The 
This article has been accepted for publication in a future issue of this journal, but has not been fully edited.

Content may change prior to final publication in an issue of the journal. To cite the paper please use the doi provided on the Digital Library page.

possibility of reducing this risk is further investigated for different volumes and speed of FRR activation. Wind power generation for 2020 and 2030 scenarios for Continental Europe (CE) network are investigated using this methodology based on which recommendations are provided for future wind power scenarios in CE network.

The structure of the paper is as following: Section 2 describes different types of frequency reserves for ENTSO-E networks. Section 3 presents the proposed methodology for estimation of adequacy of reserves. Section 4 demonstrates the implementation of proposed methodology for CE Network for wind power scenarios of 2020 and 2030. Finally, section 5 concludes the article and provides direction for future research.

\section{Frequency Reserves}

It is the responsibility of each TSO to maintain the frequency of their own control area within a predefined range as well as to honour the inter-area power transfer commitment. Therefore, whenever there is an imbalance in generation and load in own control area, the imbalance is handled using FRR. However, it should be noted that FRR activation can also be manual as it is in Nordic synchronous network. Whereas in some synchronous networks like CE, FRR activation is typically through automatic Load Frequency Control (LFC). Nevertheless, the general activation time requirement for FRR activation is that it should be fast enough to restore the frequency back to its nominal value ranging from seconds to minutes. Full FRR activation is required to be done within 15 minutes for CE and Nordic network and 10 minutes for UK network [19]. The maximum volume of FRR is limited based on agreements and decided based on maximum anticipated load combined with statistical evaluation of the deviations in the specific control area. Therefore replenishment of activated FRR is required in order to handle further power imbalances in the system. This function is achieved through RR activation. Generally, RR are activated manually by the operators and therefore takes 10-15 minutes for activation. Whenever there are imbalance prognoses in the system, the operators take decisions on RR activations. Based on these decisions, $\mathrm{RR}$ are activated. The rational for activating RR based on prognoses is to take time delays between decision and real-time activation process of these reserves into account.

However, since there is a delay of few minutes before FRR is fully deployed, power imbalances are handled instantaneously using FCR. The purpose of FCR is to contain the system frequency deviation following a large disturbance within a pre-defined range. Generally, FCR are activated within 30s after the disturbance [5] and the volume of FCR are designed based on certain reference incident like dimensional fault. Currently, the required volume of FCR for CE network is 3000 MW.

Automatic FRR are more expensive than manual FRR and RR, but cheaper than FCR. Therefore, it should always be tried to limit FCR dimension by activating more FRR and RR if required. It is important to note that traditionally all the reserves are deployed from conventional generators. However, in future European power systems with large penetration of wind power plants (WPP), reserves can also be deployed from WPPs. Although, in order to provide negative reserves WPPs may need to be downregulated. Downregulation of WPP incurs financial loss since maximum available power is not produced. However, the work in this paper is concerned on volume of reserve required and not on sources of reserves. 
This article has been accepted for publication in a future issue of this journal, but has not been fully edited.

Content may change prior to final publication in an issue of the journal. To cite the paper please use the doi provided on the Digital Library page.

\section{Methodology}

\subsection{Existing Ramp Rate based Reserve Estimation Method [16, 18]}

The definition of reserve requirements applied by Sorensen et. al. [16] are based on the definition of regulation applied by Parson et al. [18]. In this method, reserve requirements are quantified based on wind power ramping rates which is defined as the difference between the initial mean value of any considered period and the minimum value in the next period.

$$
P_{n, i}^{\text {reserve }}=P_{n, i}^{\text {mean }}-P_{n-1, i}^{\text {min }}
$$

- $P_{n, i}^{\text {reserve: }}$ Reserve requirements for time window $n$ for each control area $i$

- $P_{n, i}^{\text {mean}}$ : Mean power generation for time window $n$ for each control area $i$

- $P_{n-1, i}^{\min }:$ Minimum power generation for time window $n$ for each control area $i$

Generally, time window $n$ for ramp rate is chosen as $10-15$ minutes. Therefore, it is expected that FRR will handle this kind of imbalance. FRR is dimensioned in this method so that FRR can handle 99 percentile of imbalance $P_{n, i}^{\text {reserve }}$ for each control area as given in Equation 1. In this work, $n$ is chosen as 15 minutes.

$$
\operatorname{Pr}\left[\left|P_{i}^{\text {reserve }}\right|>R_{i}\right]<0.01
$$

- $R_{i}$ : Recommendation for FRR for control area $i$ in MW

Notice that FRR size $R_{i}$ for each control area $i$ will vary substantially since wind power generation scenario varies largely for different control areas. In order to compare this existing method with proposed method in this paper maximum of the ratio of $R_{i}$ to present dimension of FRR is considered and denoted as $K_{\text {wind,ramp }}$.

$$
K_{\text {wind,ramp }}=\operatorname{Max}\left[\frac{R_{i}}{R_{\text {present }, i}}\right]
$$

- $K_{\text {wind,ramp }}$ : Ratio of FRR dimension in future wind power scenario as compared to present system based on existing ramp rate based reserve estimation method [16] in p.u.

- $R_{\text {present }}$ : Dimensioning of FRR for control area $i$ in MW as it is in present system

This method is conservative method. This method does not consider the details of activation of RR based on wind power forecast. Furthermore, in this method FRR are dimensioned so that wind power imbalances are handled 99 percentile of time and FCR are not activated. While in the proposed method in next section, FRR are dimensioned to handle imbalances by FCR, FRR and $\mathrm{RR}$ in order to maintain the frequency with the required bandwidth. Therefore, it is expected that $K_{\text {wind,ramp }}$ obtained from this existing ramp rate based reserve estimation method [16] will have higher value as compared to the proposed method.

\subsection{Proposed Reserve Estimation Method}

Figure 1 depicts the flowchart of the proposed methodology. For the studies in this article, the methodology depicted in Figure 1 is modelled as according to the rules and regulations of $\mathrm{CE}$ 
This article has been accepted for publication in a future issue of this journal, but has not been fully edited.

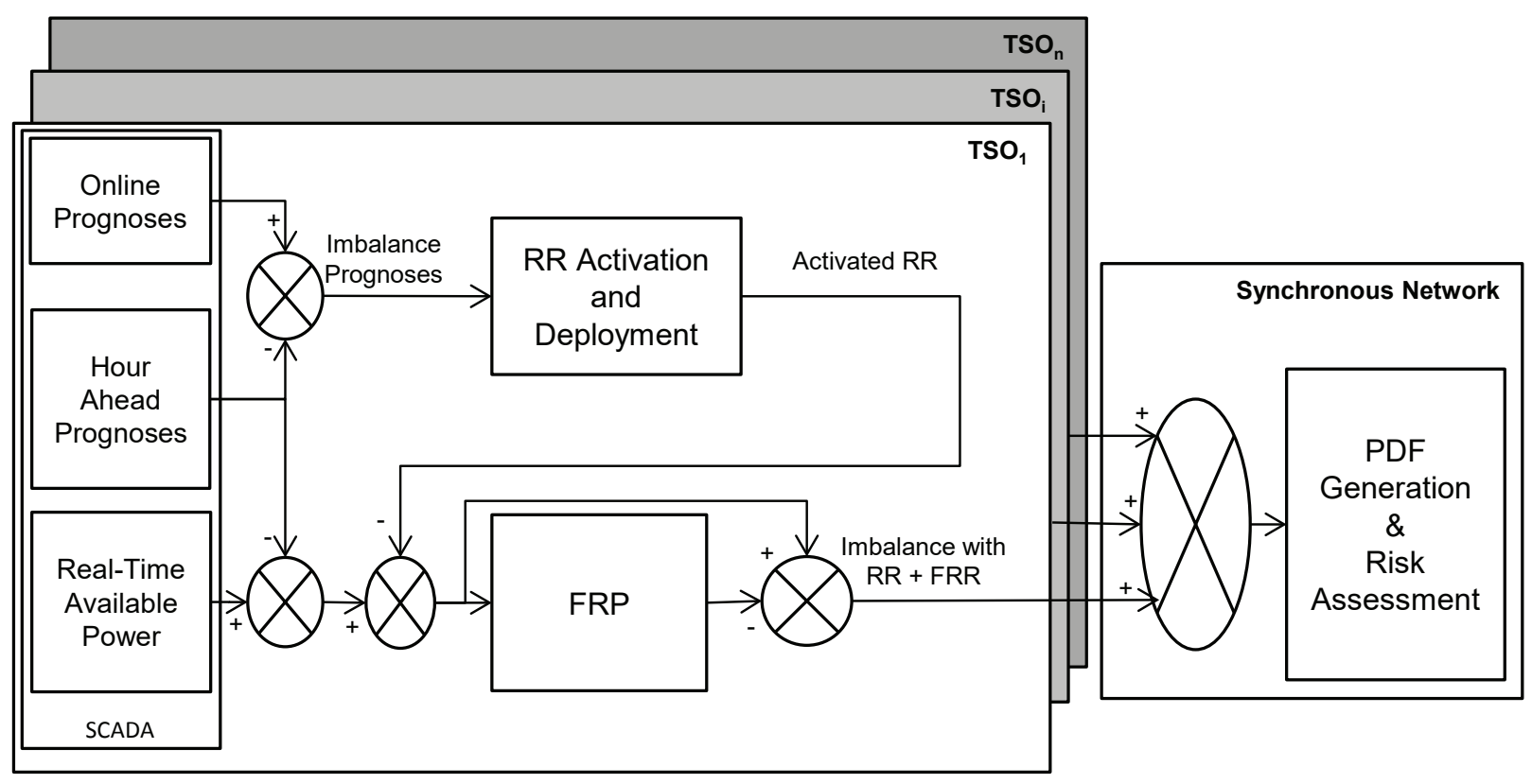

Fig. 1: Flowchart of the system model

network. Although, it should be noted that the methodology discussed is generic and can be applied for other synchronous networks. Also in these studies, each country of CE network is assumed as a single TSO or control area.

At the beginning of the operating hour, each control area is assumed to be balanced through hour-ahead power trading. Power trading and hence, unit commitment of all generators are based on the hour-ahead prognoses of the wind power generation. Error in forecast decreases as it approaches nearer to the operating time. Therefore, hour-ahead prognoses are generally expected to have higher error than online prognoses. When online prognoses of wind power generation are obtained certain $T$ minutes ahead of the operation time, imbalance prognoses are computed for each control area as the difference between online prognoses and hour-ahead prognoses. These power imbalances are handled by FCR and FRR in real-time.

3.2.1. RR activation based on imbalance prognoses: Since RR activation has certain delay in activation process, therefore operators generally need to take decisions beforehand to activate RR in order to replenish FRR. Figure 2 depicts the RR activation and deployment block from the flowchart in Figure 1. As soon as the decision to activate RR is taken, imbalance prognoses are updated taking into consideration of this activation plan.

Total imbalance prognose is given by Equation 4.

$$
I_{t+T, i}^{\text {Prognose }}=P_{t+T, i}^{\text {online }}-P_{t+T, i}^{H A}-P_{t+T, i}^{R R_{\text {signal }}}
$$

- $I_{t+T, i}^{\text {Prognose }}$ : Total imbalance prognose at time instant $t+T$ for each control area $i$

- $P_{t+T, i}^{o n l i n e}:$ Total online power prognose at time instant $t+T$ for each control area $i$

- $P_{t+T, i}^{H A}$ : Total hour-ahead power prognose at time instant $t+T$ for each control area $i$ 
This article has been accepted for publication in a future issue of this journal, but has not been fully edited.

Content may change prior to final publication in an issue of the journal. To cite the paper please use the doi provided on the Digital Library page.

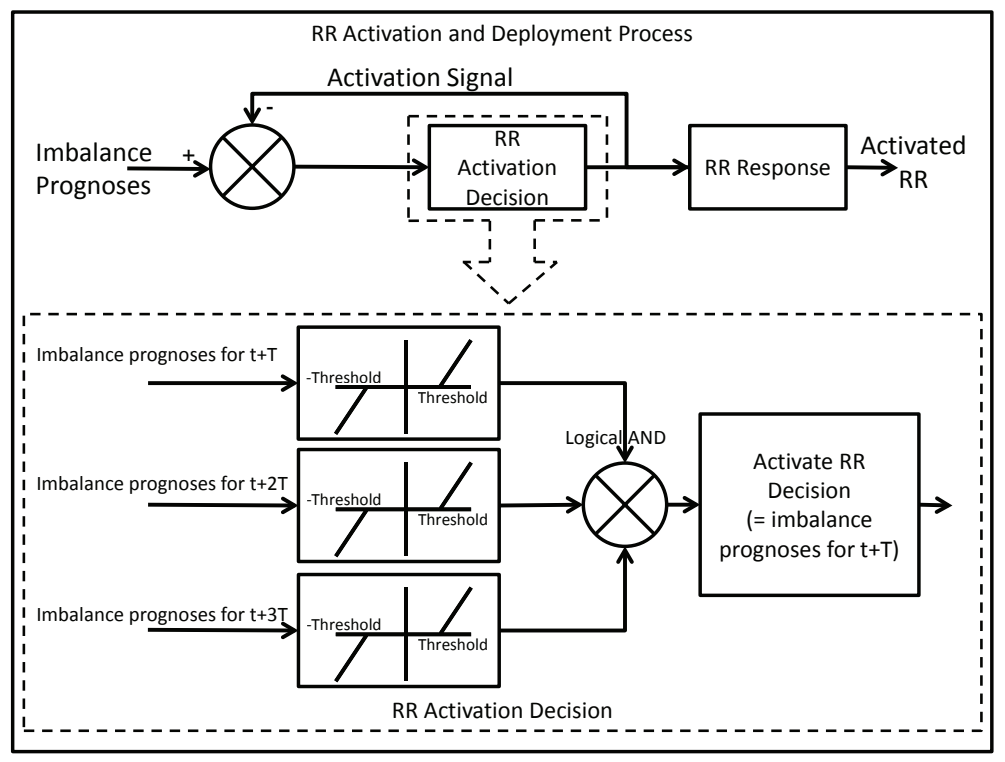

Fig. 2: RR Activation and Deployment Block

- $P_{t+T, i}^{R R_{\text {signal }}}:$ Total already activated RR based on the previous activation signals sent by operators at time instant $t+T$ for each control area $i$

The proposed RR activation decision blocked from Figure 2 is also shown in Figure 2.

It depicts that the operators need to be certain that the imbalance prognoses are not random noises. Therefore if imbalance prognoses are found to be greater than a threshold value for next $3 T$ minutes, then RR is activated to mitigate the power imbalance. Threshold can be decided based on experience of the operators.

Since, RR sources are activated manually and are generally slow therefore RR response is delayed from the activation plan. RR responses are modelled with delay of $T$ minutes followed by ramping up in $2 T$ minutes.

3.2.2. Frequency Restoration Process $(F R P)$ during real-time operation: During real-time operation power imbalance is computed as the difference between real-time available wind power generations and hour-ahead prognoses.

$$
I_{t, i}^{\text {realtime }} \text { wo_Res }=P_{t, i}^{\text {realtime }}-P_{t, i}^{H A}
$$

However, since RR is already activated and deployed based on imbalance prognose, $I_{t+T, i}^{\text {Prognose }}$ as given in Equation 4. Therefore, real-time power imbalance from Equation 5 is modified to $I_{t, i}^{\text {realtime }}{ }_{R R}$ as given in Equation 6.

$$
I_{t, i}^{\text {realtime }} \text { RR }=P_{t, i}^{\text {realtime }}-P_{t, i}^{H A}-P_{t, i}^{R R_{\text {activated }}}
$$

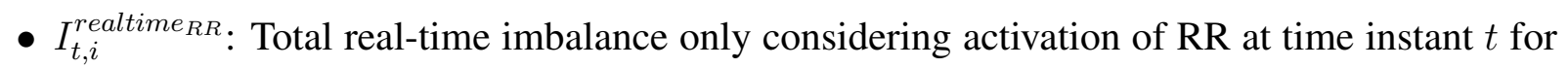
each control area $i$

- $P_{t, i}^{\text {realtime }}$ : Total real-time available wind power generated at time instant $t$ for each control area $i$. 
This article has been accepted for publication in a future issue of this journal, but has not been fully edited.

Content may change prior to final publication in an issue of the journal. To cite the paper please use the doi provided on the Digital Library page.

- $P_{t, i}^{H A}$ : Total hour-ahead power prognose at time instant $t$ for each control area $i$

- $P_{t, i}^{R R_{\text {activated }}}$ : Total activated and deployed RR at time instant $t$ for each control area $i$

This real-time power imbalance considering RR activation and deployment needs to be handled using FCR and FRR. FRR is assumed to be activated by automatic LFC in this methodology. LFC control is modelled with an anti-windup PI controller along with measurement filter as shown in Figure 3. Filter is modelled as a first order transfer function with time constant $T_{\text {filter }}$. Real-

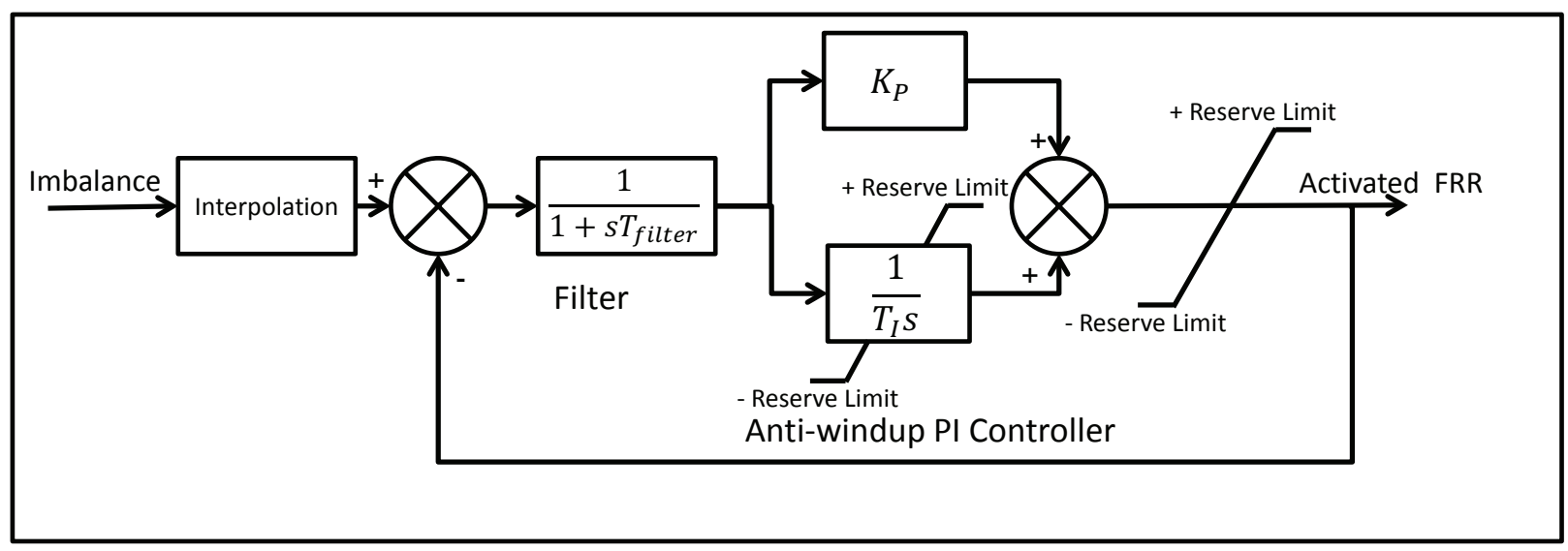

Fig. 3: Frequency Restoration Process

time imbalance input to the FRP is of $T$ minute resolution. Since, FRP has faster response, the imbalance is interpolated to 10 seconds resolution which is input to the anti-windup PI controller as shown in Figure 3.

Sizing of FRR: $\quad$ Different methodologies for dimensioning of FRR are defined in "P1-Policy 1: Load-Frequency Control and Performance [C]" of UCTE operation handbook [20] based on different operational needs in control areas of LFC, due to different characteristics and patterns of generation (including hydraulic, thermal and HVDC- link) and demand (including BRP and forecast qualities). The sizing of the FRR is done by deterministic and / or probabilistic approaches as following:

1. Empiric Noise Management Sizing Approach - The FRR for each control area is computed based on [5], [20]

$$
R=\sqrt{a L_{\max }+b^{2}}-b
$$

Where,

- $R$ : Recommendation for control Reserve in MW

- $L_{\max }$ : Maximum anticipated load in MW for the control area

The parameters, $a$ and $b$ are empirically assumed as: $a=10 \mathrm{MW}$ and $b=150 \mathrm{MW}$ [20]

2. Probabilistic Risk Management Sizing Approach - For the probabilistic assessment European Commission's guideline on electricity transmission system operation defines a minimum value for the sum of FRR Capacity and RR Capacity which is defined by the $99 \%$ quantile of the LFC Block Imbalances (separate for positive and negative direction) [6]. 
This article has been accepted for publication in a future issue of this journal, but has not been fully edited.

Content may change prior to final publication in an issue of the journal. To cite the paper please use the doi provided on the Digital Library page.

3. Largest Generation Unit or Power Infeed - The sizing is done based on largest possible generation incident for each control area.

4. Extra-ordinary Sizing of Reserves - Other criteria e.g. consideration of large changes in exchanges, expected load variations, adverse climatic conditions, strikes etc. might influence the size of the reserve.

In these studies, Empiric Noise Management Deterministic Sizing Approach and Probabilistic Risk Management Sizing Approach are used for dimensioning of FRR. Therefore, Equation 7 is modified to include a multiplying factor $K_{\text {wind }}$ so that the imbalance caused by wind power generation can be handled statistically $99 \%$ of the time by FCR.

$$
R=K_{\text {wind }}\left(\sqrt{a L_{\text {max }}+b^{2}}-b\right)
$$

$K_{\text {wind }}$ basically signifies amount of FRR required in future as compared to present value and given as the ratio of future FRR dimension in p.u. to present FRR dimension taken as base value. For example, a value of 2 for $K_{\text {wind }}$ means that in future FRR should be dimensioned double as compared to present value in order to handle imbalances due to wind power forecast error.

FRR dimension as estimated based on Equation 8 is used as Reserve Limit in the flowchart shown in Figure 3.

\subsubsection{Risk estimation of FCR exceeding design requirements for synchronous network:} The power imbalances which occur either if the LFC is yet to be activated or if FRR is exhausted but RR is not yet activated are needed to be handled using FCR.

Since FCR in a synchronous network are shared among all the control areas / TSOs, therefore the power imbalances for all the control areas in each synchronous area are added together as shown in Figure 1 and given by Equation 9.

$$
I_{t}^{\text {realtime }_{F R R+R R}}=\sum_{i=1}^{n} I_{t, i}^{\text {realtime }} R R-P_{t, i}^{F R R_{\text {activated }}}
$$

- $I_{t}^{\text {realtime }} F R R+R R$ : Total realtime imbalance with activation of FRR and RR at time instant $t$ for synchronous network

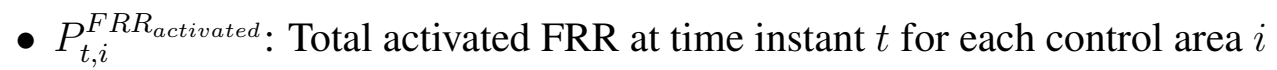

- $n$ : Total number of TSOs or control areas in the concerned synchronous network

Probability density functions of the imbalance $I_{t}^{\text {realtime }}{ }_{F R R+R R}$ provide the information about the risk of power imbalance exceeding designed FCR dimension $F C R_{\text {size }}$ (For example- FCR requirement designed based on dimensional fault for CE is $3000 \mathrm{MW}$ ). Probabilistic risk of exceeding the designed FCR dimension $F C R_{\text {size }}$ value of the synchronous network is given by Equation 10 .

$$
\begin{aligned}
\text { Risk }=\operatorname{Pr}\left[\left|I_{t}^{\text {realtime }_{F R R} R R}\right|>F C R_{\text {size }}\right] & \\
& =1-\operatorname{Pr}\left[-F C R_{\text {size }}<I_{t}^{\text {realtime }_{F R R+R R}}<F C R_{\text {size }}\right]
\end{aligned}
$$

- FCR $R_{\text {size }}$ : Designed FCR size for concerned synchronous network 
This article has been accepted for publication in a future issue of this journal, but has not been fully edited.

Content may change prior to final publication in an issue of the journal. To cite the paper please use the doi provided on the Digital Library page.

Equation 10 depicts that Risk is calculated as the probability of total realtime imbalance with activation of FRR and RR exceeding designed FCR dimension for concerned synchronous network.

In order to be able to handle imbalance with the available $F C R_{\text {size }}$ for $99 \%$ of time, the risk estimated through Equation 10 should be less than 1\% i.e 0.01. Therefore, the design criterion for dimensioning FRR for handling wind power imbalances with 1\% risk is given by Equation 11 .

$$
\begin{aligned}
\text { Risk }=\operatorname{Pr}\left[\left|I_{t}^{\text {realtime }_{F R R} R R R}\right|\right. & \left.>F C R_{\text {size }}\right] \\
& =1-\operatorname{Pr}\left[-F C R_{\text {size }}<I_{t}^{\text {realtime }_{F R R+R R}}<F C R_{\text {size }}\right]<0.01
\end{aligned}
$$

Equation 11 is the design criterion for probabilistic risk estimation algorithm. It is possible using proposed algorithm to estimate the volume and speed of FRR activation so that the probabilistic risk is less than 0.01 .

\section{Study Case - CE Network}

A set of anticipated wind power installation scenarios for ENTSO-E networks for 2020 and 2030 are developed and simulated in the following based on data from different sources such as [21, 22, 23]. These scenarios are validated based on EWEA report [1]. Figure 4 depicts the anticipated installed onshore and offshore wind power capacity and peak load in GW for different countries of ENTSO-E networks for 2020 and 2030. In 2020 scenario, offshore wind power capacity is 3 times smaller than the onshore wind power capacity, while in 2030 scenario offshore wind power capacity is less than 2 times of the onshore wind power capacity. Furthermore, in some countries, offshore wind power capacity becomes more dominant than onshore wind capacity in 2030 .

CorWind [24], a software developed in DTU Wind Energy is used to generate hour ahead forecast, online prognoses and real-time available power from the wind for each of the wind power scenarios for ENTSO-E networks. These data are simulated for each of the scenarios for 14 meteorological years.

Following are the assumptions and considerations for probabilistic risk assessment algorithm for CE:

- Online prognoses are obtained at the resolution of 5 minutes for next 15 minutes $(T=5)$.

- Each country in CE network is assumed as a control area

- Threshold for RR activation for the studies is $30 \mathrm{MW}$

- RR responses are modelled with 5 minute delay and ramping rate of 10 minutes

- Proportional gain $K_{p}$ for FRP is assumed 0.2 p.u.

- Filter time constant $T_{\text {filter }}$ is assumed as $16 \mathrm{~s}$.

- Generally, each TSO is responsible to handle power imbalances in its own control area, therefore it is assumed in these studies that that there is no contribution from neighboring control area to mitigate power imbalances in other control areas.

- The maximum anticipated loads for each control area for 2020 and 2030 scenarios are based on ENTSO-E adequacy forecast [25]. Based on the maximum anticipated load for each control area, Reserve Limit is obtained from Equation 8. Notice that since different countries have different load levels, Reserve Limit are different for all the countries. 
This article has been accepted for publication in a future issue of this journal, but has not been fully edited. Content may change prior to final publication in an issue of the journal. To cite the paper please use the doi provided on the Digital Library page.

Installed Capacity of Wind Power Generation in GW

\begin{tabular}{ccccc}
\hline \multirow{2}{*}{ Network } & \multicolumn{2}{c}{2020} & \multicolumn{2}{c}{2030} \\
& Onshore & Offshore & Onshore & Offshore \\
\hline UK & 12.5 & 9 & 19 & 32 \\
CE & 166 & 25 & 217 & 94 \\
Baltic & 0.5 & 0 & 0.5 & 5 \\
Nordic & 8 & 9 & 10 & 28 \\
Ireland & 2 & 2.5 & 1.5 & 3 \\
\hline Total & 189 & 46 & 248 & 162 \\
\hline
\end{tabular}
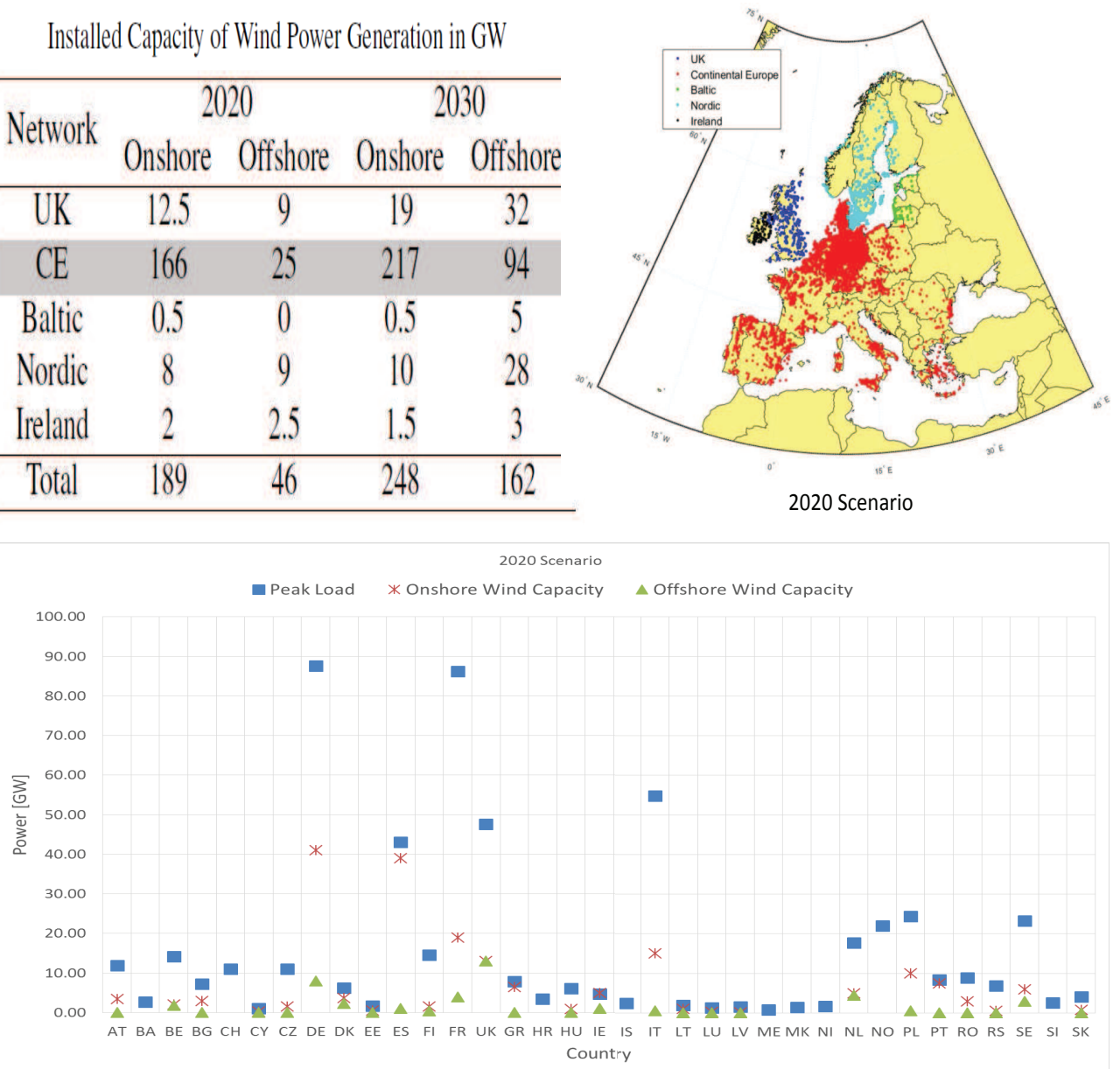

Fig. 4: Peak Load and Wind Power Scenario for different countries in ENTSO-E Networks

- The total volume of FRR for CE is around $12000 \mathrm{MW}$.

- FCR dimension designed for CE network is $3000 \mathrm{MW}$.

Simulations are performed for different FRR activation volumes and activation time. Studies are done for CE synchronous network.

\subsection{Scenario}

Reserve requirements $K_{\text {wind,ramp }}$ computed based on existing ramp rate based reserve estimation method [16] is found to be 2 p.u. for 2020 wind power scenario.

The probability density functions of imbalances for CE network for 2020 scenario is shown in Figure 5(a) for 2 cases- one without reserve activation, realtime $_{w / o-R e s}$ (Equation 5) and one with FRR + RR activation, $I^{\text {realtime }_{F R R+R R}}$ (Equation 9). It is observed that the probability density function curve for imbalance becomes much narrower after activation of FRR and RR. This implies that probabilities of power imbalances decrease with activation of FRR and RR.

The tail of the probability density function curve is long even after activation of reserves. This signifies that there is a very low probability of extreme high power imbalances. In order to handle such extreme situations, a very high amount of FCR are required. This advocates for dynamic 
This article has been accepted for publication in a future issue of this journal, but has not been fully edited.

Content may change prior to final publication in an issue of the journal. To cite the paper please use the doi provided on the Digital Library page.

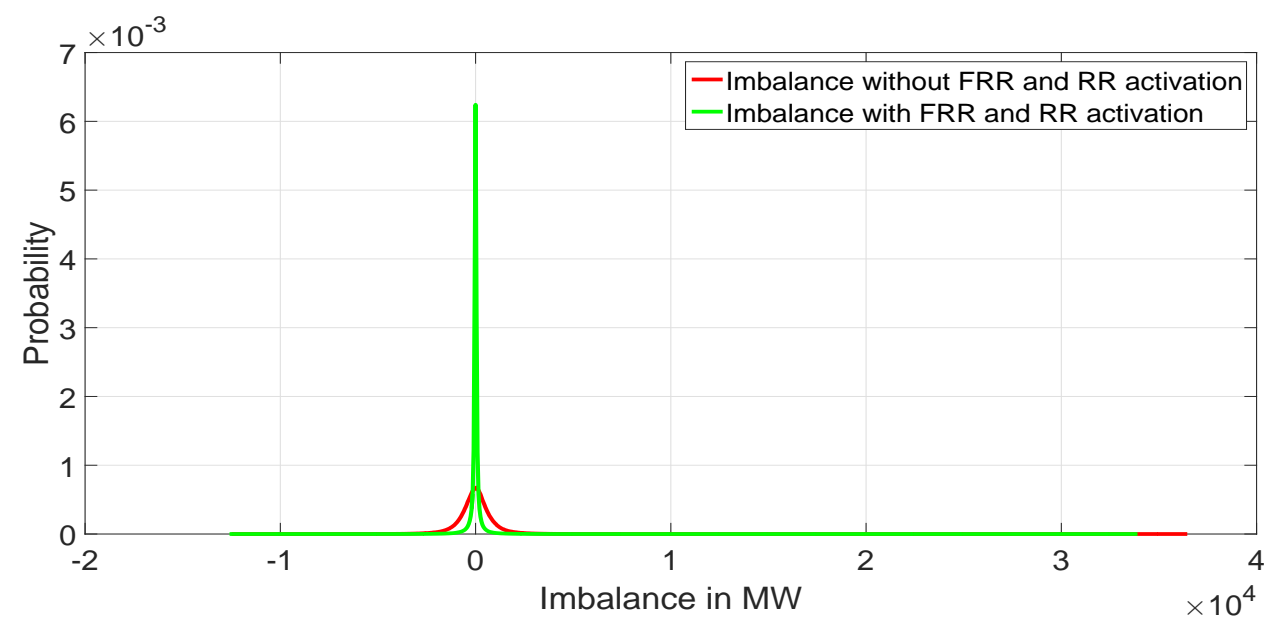

(a)

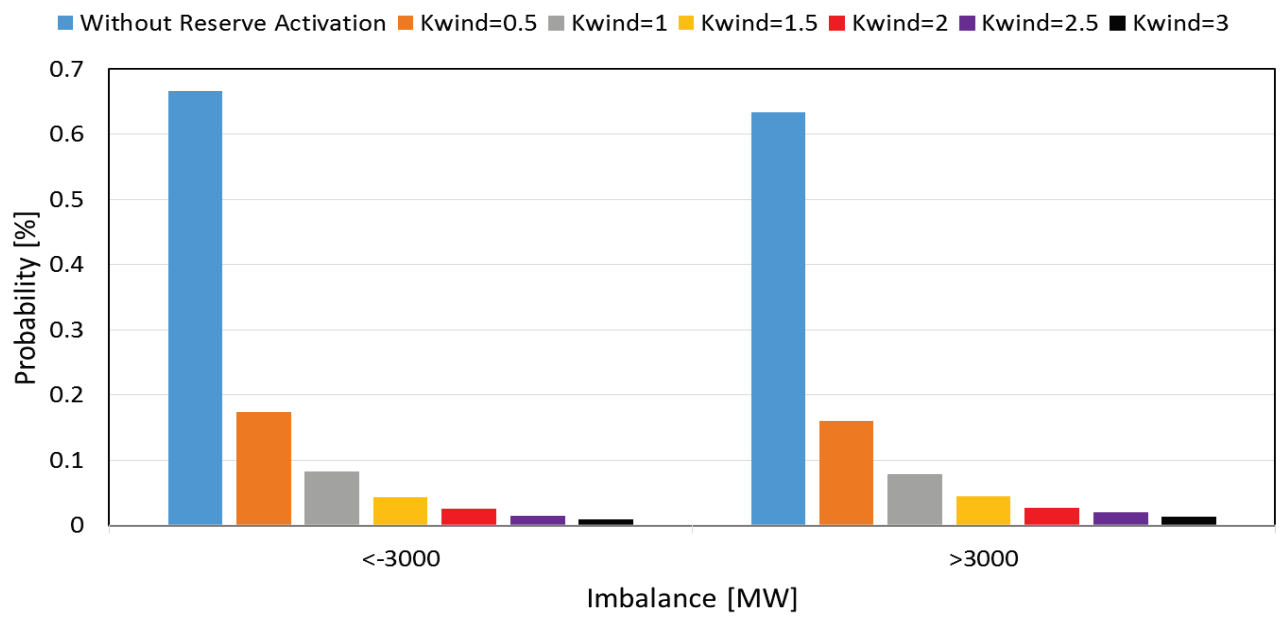

(b)

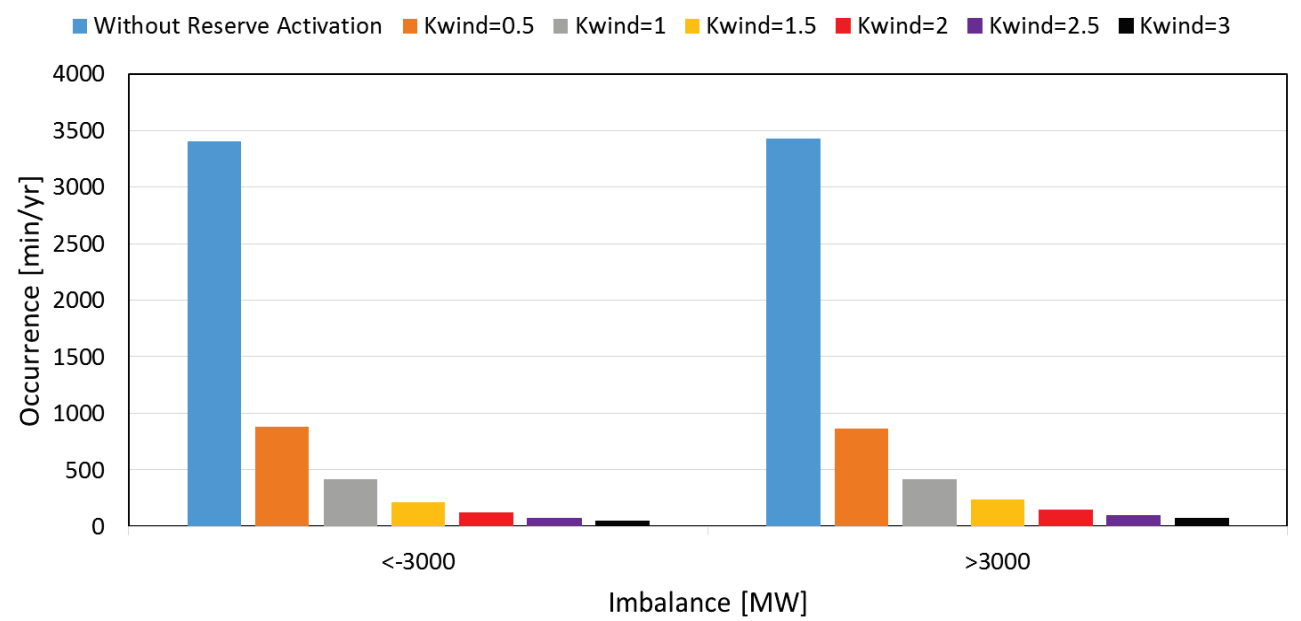

(c)

Fig. 5: (a) Probability density functions of power imbalances with and without reserve activations (b) Probability of power imbalance exceeding $3000 \mathrm{MW}$ (c) Occurrence of power imbalance exceeding $3000 \mathrm{MW}$ for CE for 2020 scenario for different volumes of FRR activation 
This article has been accepted for publication in a future issue of this journal, but has not been fully edited.

Content may change prior to final publication in an issue of the journal. To cite the paper please use the doi provided on the Digital Library page.

deployment of FCR to handle such rare scenarios.

Figure 5(b) shows the probability of the imbalance exceeding FCR dimension (3000 MW) for CE for different volumes of FRR activation in 2020 scenario. As mentioned before, $K_{\text {wind }}$ is the scaling factor representing the volume of FRR dimension for considered wind power scenario as compared to present system. Note that FCR will be activated only if either imbalance happens before FRR is activated or FRR is exhausted and RR is not activated yet. Therefore, different volume and speed of activation of FRR are studied in this paper. It is observed that probability of imbalance exceeding $3000 \mathrm{MW}$ for 2020 scenario is quite low (less than 1\%). Therefore, power imbalances can be handled more than $99 \%$ of the time using the FRR dimensioned as it is in present condition. However, higher the value of $K_{\text {wind }}$ i.e. higher the volume of available FRR, lower is the probability of power imbalance beyond $3000 \mathrm{MW}$.

Another important point to be considered is the amount of time power imbalance is exceeding the standard range. Figure 5(c) shows occurrence of the power imbalance exceeding reference incident for CE for 2020 scenario. Occurrences are much less than the required criterion of 15000 $\mathrm{min} / \mathrm{yr}$ [26]. Higher the value of $K_{\text {wind }}$, lower is the occurrence of power imbalance beyond 3000 MW. Occurrence decreases substantially from $3350 \mathrm{~min} / \mathrm{yr}$ for power imbalance without reserve activation to $35 \mathrm{~min} / \mathrm{yr}$ for reserve activation with $K_{\text {wind }}=3 p . u$. for positive power imbalance exceeding $3000 \mathrm{MW}$.
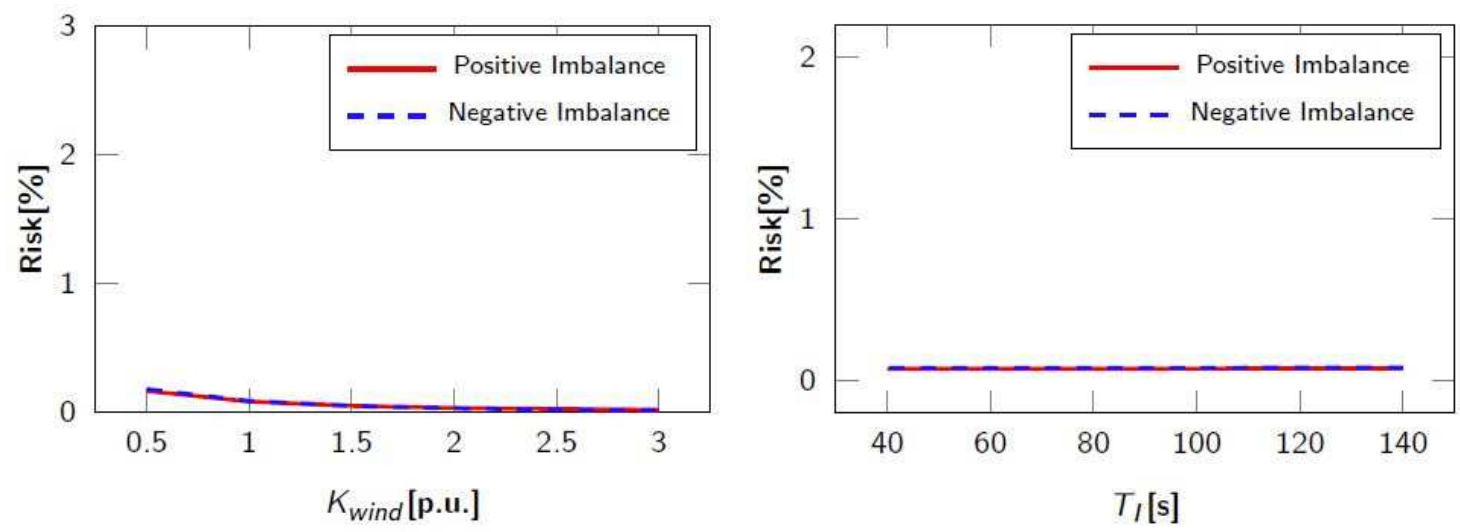

Fig. 6: Risk of power imbalance exceeding $3000 \mathrm{MW}$ for CE for 2020 scenario for different FRR activation

The probabilistic risk for different volumes and different integration time constants of FRR activation for negative and positive power imbalances are shown in Figure 6. Probabilistic risk is plotted against $K_{\text {wind }}$ (volume of FRR) and $T_{I}$ (speed of activation). Remark that risk of power imbalance exceeding $3000 \mathrm{MW}$ is similar for both positive and negative imbalance. It can be observed that risk of imbalances exceeding $3000 \mathrm{MW}$ is much lower than $1 \%$. However, $T_{I}$ does not have impact in reducing power imbalance due to wind forecast error. $K_{\text {wind }}$ has significant impact in reducing risk and risk reduces exponentially with increase in volume of FRR and remains almost unaffected by increase in integration time constant of FRR activation.

\subsection{Scenario}

Reserve requirements $K_{\text {wind,ramp }}$ computed based on existing ramp rate based reserve estimation method [16] is found to be 5 p.u. for 2030 wind power scenario.

Figure 7(a) shows the probability of the power imbalance exceeding $3000 \mathrm{MW}$ for CE for 
This article has been accepted for publication in a future issue of this journal, but has not been fully edited.

Content may change prior to final publication in an issue of the journal. To cite the paper please use the doi provided on the Digital Library page.

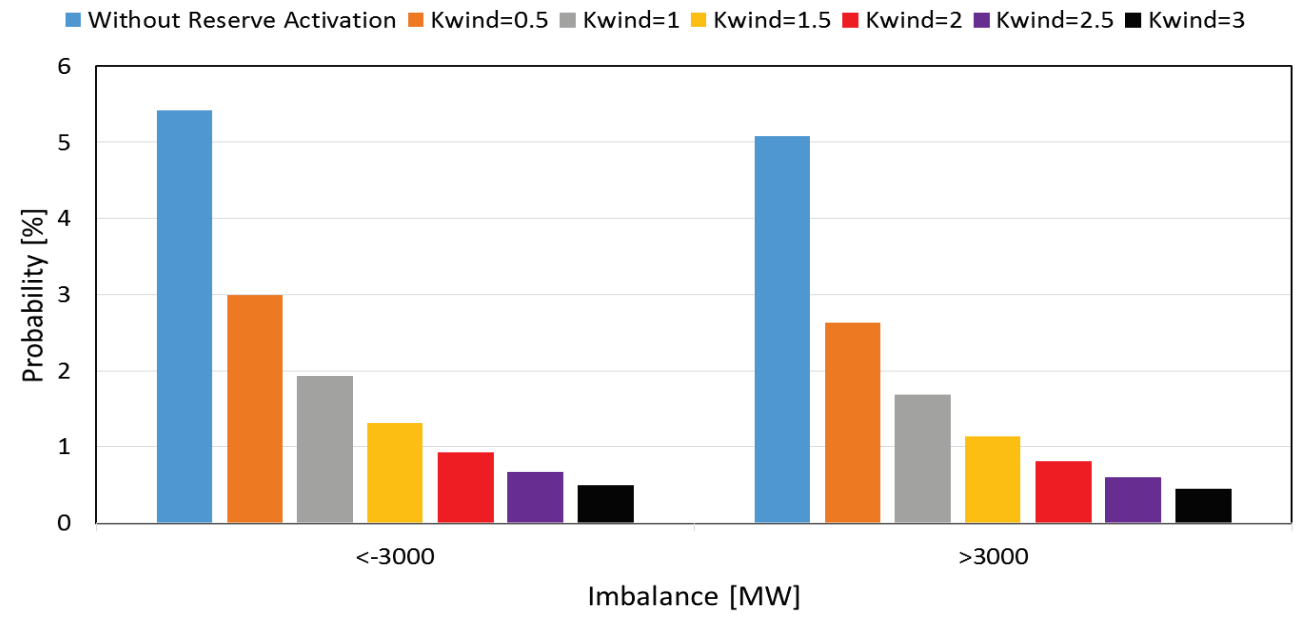

(a)

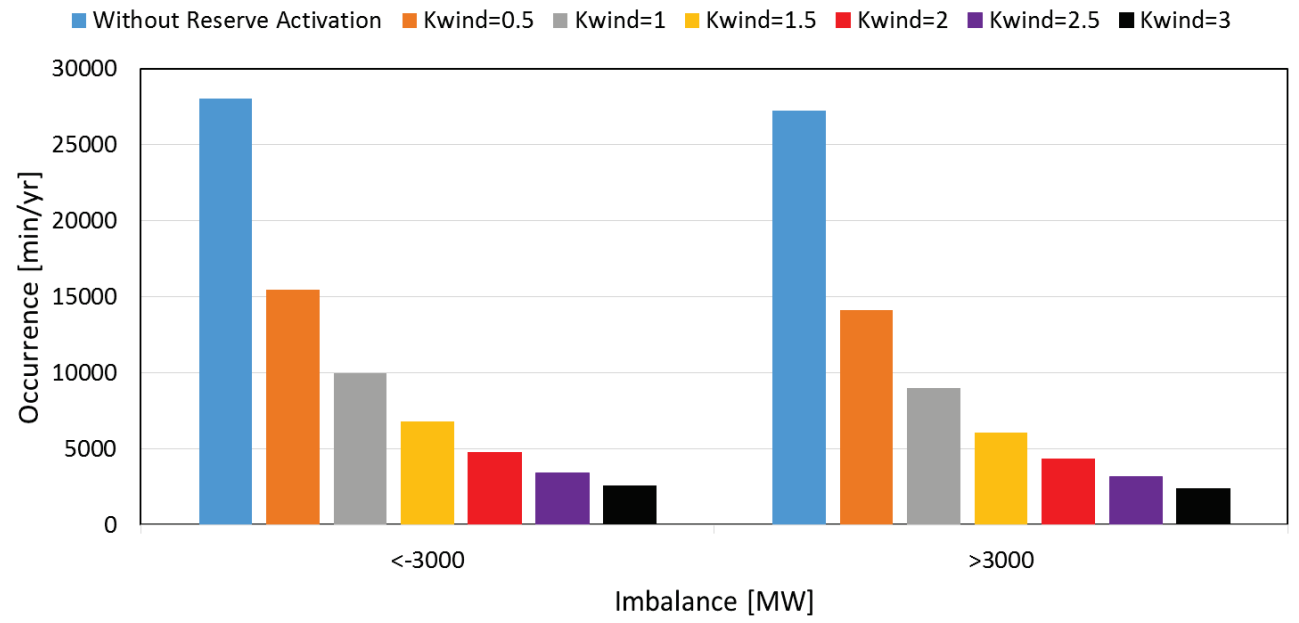

(b)

Fig. 7: (a)Probability (b)Occurrence of imbalance exceeding $3000 \mathrm{MW}$ for CE for 2030 scenario

different volumes of FRR activation for 2030 scenario. In contrast to 2020 scenario, probability of the power imbalance exceeding $3000 \mathrm{MW}$ is almost 10 times higher. Power imbalance without reserve activation exceeding $3000 \mathrm{MW}$ caused by error in wind power forecast is higher than $5 \%$. This imbalance reduces substantially with activation of FRR and RR from 5\% to $0.5 \%$ when volume of FRR is increased by three times as that of present system i.e. $K_{\text {wind }}=3$. If $K_{\text {wind }}=0.5$ i.e. half of the FRR is already employed to handle other kinds of power imbalances from loads, contingencies, other generations etc., then the imbalance due to wind power can be as high as $3 \%$. With $100 \%$ of the available FRR dimensioned (i.e. $K_{\text {wind }}=1$ ) as it is in present system, imbalance comes down just below to $2 \%$. This implies that over-dimensioning of FRR is essentially required to handle wind power imbalances in 2030 scenario. By dimensioning FRR double $\left(K_{\text {wind }}=2\right)$ as that of present volume, imbalance reduces down to less than $1 \%$. Increasing the FRR dimension to three times $\left(K_{\text {wind }}=3\right)$, the power imbalances due to wind reduces to less than $0.5 \%$, which is equivalent to power imbalance in 2020 scenario.

This result can be interpreted as volume of FRR plays important role in reducing the imbalances 
This article has been accepted for publication in a future issue of this journal, but has not been fully edited.

Content may change prior to final publication in an issue of the journal. To cite the paper please use the doi provided on the Digital Library page.

due to wind power forecast error. This is expected since ramping of wind power is a phenomenon which takes generally around 10-15 minutes. In this time period, FRR plays the role of balancing and load following. Lower value of $K_{\text {wind }}$ i.e. lower volume of FRR does not reduce the imbalance thereby demonstrating that FRP of Fig. 3 reaches the saturation limit (Reserve Limit) Another point of consideration is that the power imbalances exceeding $3000 \mathrm{MW}$ should not be more than $15000 \mathrm{~min} / \mathrm{yr}$. Figure 7(b) shows the occurrence of power imbalance due to wind power exceeding $3000 \mathrm{MW}$ for CE for 2030 scenario. Power imbalances without FRR and RR activation occur much more frequently than $15000 \mathrm{~min} / \mathrm{yr}$. It does not came below $15000 \mathrm{~min} / \mathrm{yr}$ with half $\left(K_{\text {wind }}=0.5\right)$ of the FRR activated to handle wind power imbalances. However, with $100 \%$ of the FRR utilised to handle power imbalances due to wind, occurrences of power imbalances become less than 15000 $\min / \mathrm{yr}$.
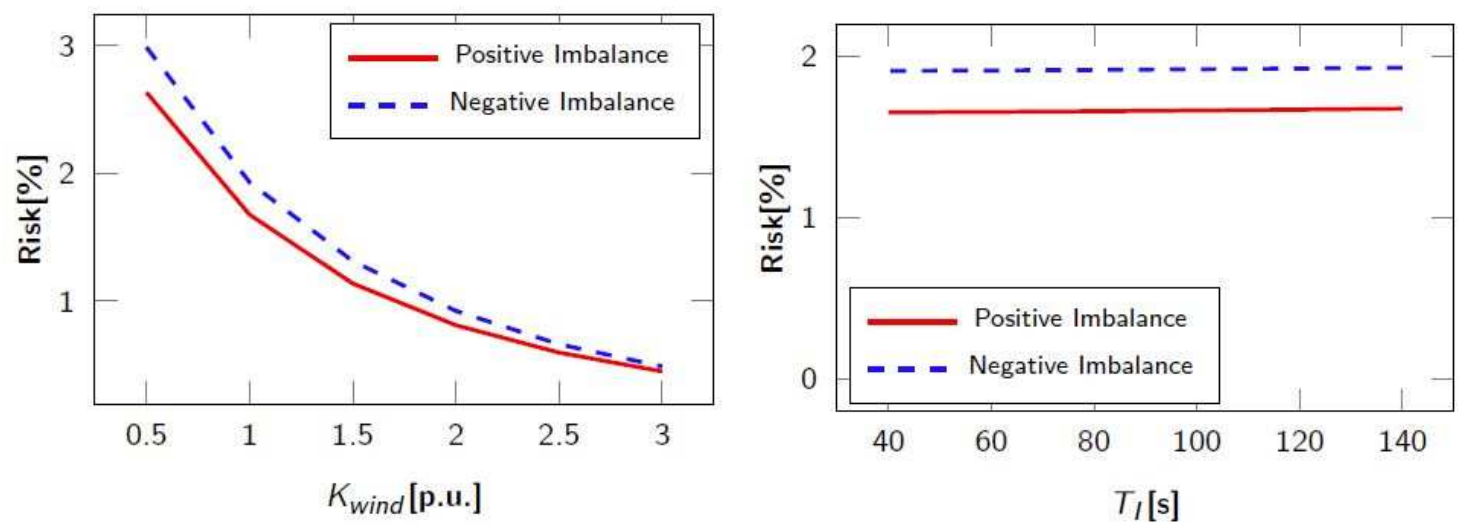

Fig. 8: Risk of power imbalance exceeding $3000 \mathrm{MW}$ for CE for 2030 scenario

Probabilistic risk of positive and negative power imbalances exceeding $3000 \mathrm{MW}$ for different volumes and different speed of FRR activation are shown in Figure 8. Similar to observation of 2020 scenario, the risk reduces exponentially with increase in volume of FRR and remains almost unaffected by increase in integration time constant of FRR activation for 2030 scenario. Speed of FRR activation does not have significant improvement in reduction of imbalances implying that speed of FRP in present condition is sufficient to handle these imbalances. This is expected since ramping of wind power takes around 10 to 15 minutes.

It is observed that $K_{\text {wind }}$ should at least be 2 p.u. in order to bring the risk lower than $1 \%$. Furthermore, there is substantial improvement as compared to $K_{\text {wind,ramp }}$ obtained from existing method from literature [16]. The proposed methodology provides improved and more practical solution for reserve requirements.

\section{Conclusion}

A new methodology has been presented in this article to study the adequacy of frequency reserves for future power systems with high penetration of wind power generation. The wind power forecast is developed based on current practice in the TSOs. However, if better short term forecasts are available in future, the requirements for reserves can be reduced. The studies presented in this work only considers imbalance caused by wind power forecasts. Imbalances caused from other sources like load, other stochastic generations like solar PV, contingencies etc. are not considered in this work and can be considered in future works. The proposed and developed methodology 
This article has been accepted for publication in a future issue of this journal, but has not been fully edited.

Content may change prior to final publication in an issue of the journal. To cite the paper please use the doi provided on the Digital Library page.

estimates adequacy of reserves for wind power scenarios through probabilistic risk assessment. Probabilistic risk assessment of power imbalances exceeding designed frequency containment reserves with activation of frequency restoration and replacement reserves demonstrates that risk for wind scenarios for Continental Europe reduces exponentially with increase in volume of frequency restoration reserves and remains almost unaffected by increase in speed of frequency restoration reserve activation. Probability of power imbalance due to wind forecast error exceeding $3000 \mathrm{MW}$ for Continental Europe network in 2020 scenario can be low and can be handled with reserves dimensioned as it is in present system. While risk of power imbalance exceeding $3000 \mathrm{MW}$ for 2030 wind power scenario in Continental Europe can be high. Therefore, frequency restoration reserves for countries with high wind power penetration of 2030 scenario should have additional volume (at least 2 times higher than reserve volume in present scenario) in order to handle power imbalances from wind power forecast error.

\section{Acknowledgment}

The research leading to these results has received funding from the European Union Seventh Framework Programme (FP7/2007-2013) under grant agreement $n^{\circ}$. 283012. Authors would also like to acknowledge their thanks to Martin Høgdahl Zamastil from Energinet.Dk for his feedback and support.

\section{References}

[1] EWEA, "Pure Power," 2011. [Online]. Available: http://www.ewea.org/fileadmin/files/ library/publications/reports/Pure Power_III.pdf

[2] K. Das, A. D. Hansen, and P. E. Sørensen, "Aspects of Relevance of Wind Power in Power System Defense Plans," in 12th International Workshop on Large-Scale Integration of Wind Power into Power Systems as well as on Transmission Networks for Offshore Wind Power Plants, 2013, pp. 416-421.

[3] S. De Boeck, K. Das, V. Trovato et al., "Review of defence plans in europe: Current status, strenghts and opportunities," CIGRE Science \& Engineering, vol. 5, pp. 2-11, 2016.

[4] K. Das, A. Nitsas, M. Altin, A. D. Hansen, and P. Sørensen, "Improved Load Shedding Scheme considering Distributed Generation," IEEE Transactions on Power Delivery, 2016.

[5] UCTE, "Operation Handbook," Union for the Co-ordination of Transmission of Electricity, Tech. Rep., June 2004.

[6] EUROPEAN COMMISSION, "A guideline on electricity transmission system operation,” 2016. [Online]. Available: https://www.entsoe.eu/major-projects/network-codedevelopment/system-operation/Pages/default.aspx

[7] Nordel, "Nordic Grid Code (Nordic collection of rules)," 2007. [Online]. Available: https://www.entsoe.eu/fileadmin/user_upload/_library/publications/nordic/planning/ 070115_entsoe_nordic_NordicGridCode.pdf 
This article has been accepted for publication in a future issue of this journal, but has not been fully edited.

Content may change prior to final publication in an issue of the journal. To cite the paper please use the doi provided on the Digital Library page.

[8] M. Milligan, P. Donohoo, D. Lewothers et al., "Operating Reserves and Wind Power Integration:An International Comparison," in Proceedings of 9th International Workshop on Large-Scale Integration of Wind Power into Power Systems, Oct 2010.

[9] E. Ela, M. Milligan, and B. Kirby, “Operating Reserves and Variable Generation,” NREL/TP5500-51928, August 2011.

[10] E. Ela, B. Kirby, E. Lannoye et al., "Evolution of Operating Reserve Determination in Wind Power Integration Studies," in Proceedings of IEEE PES General Meeting, July 2010.

[11] H. Holttinen, M. Milligan, E. Ela et al., "Methodologies to Determine Operating Reserves due to Increased Wind Power," IEEE Transactions on Sustainable Energy, vol. 3, no. 4, pp. 713-723, 2007.

[12] J. Kiviluoma, M. O’Malley, A. Tuohy et al., "Impact of wind power on the unit commitment, operating reserves, and market design," in Proceedings of IEEE PES General Meeting, July 2011, pp. 1-8.

[13] A. Botterud, Z. Zhou, J. Wang et al., "Unit commitment and operating reserves with probabilistic wind power forecasts," in Proceedings of IEEE PowerTech, Trondheim, 2011.

[14] N. Menemenlis, M. Huneault, and A. Robitaille, "Computation of Dynamic Operating Balancing Reserve for Wind Power Integration for the Time-Horizon 1-48 Hours," IEEE Transactions on Sustainable Energy, vol. 3, no. 4, pp. 692-702, 2012.

[15] K. Das, M. Litong-Palima, P. Maule, and P. E. Sørensen, "Adequacy of Operating Reserves for Power Systems in Future European Wind Power Scenarios," in IEEE PES General Meeting, July 2015.

[16] P. Sorensen, N. A. Cutululis, A. Vigueras-Rodríguez, L. E. Jensen, J. Hjerrild, M. H. Donovan, and H. Madsen, "Power fluctuations from large wind farms," IEEE Transactions on Power Systems, vol. 22, no. 3, pp. 958-965, 2007.

[17] P. Sorensen, M. Litong-Palima, A. N. Hahmann, S. Heunis, M. Ntusi, and J. C. Hansen, "Wind power variability and power system reserves," in invited paper to be published in WindAC Africa, 2016.

[18] B. Parsons, M. Milligan, B. Zavadil et al., "Grid impacts of wind power: a summary of recent studies in the United States," Wind Energy, vol. 7, no. 2, pp. 87-108, 2004.

[19] ENTSO-E, "Network Code on Load Frequency Control and Reserves (LFCR)." [Online]. Available: https://www.entsoe.eu/major-projects/network-code-development/loadfrequency-control-reserves/Pages/default.aspx

[20] Handbook, UCTE Operations, "P1-Policy 1: Load-Frequency Control and Performance [C]," march 2009. [Online]. Available: https://www.entsoe.eu/fileadmin/user_upload/_library/ publications/entsoe/Operation_Handbook/Policy_1_final.pdf

[21] 4COffshore, "Global Offshore Wind Database." [Online]. Available: http://www.4coffshore. com/windfarms/

[22] TheWindPower, "Wind Farms List." [Online]. Available: http://www.thewindpower.net/ windfarms_list_en.php 
[23] N. A. Cutululis, M. Litong-Palima, L. Zeni, A. Gøttig, N. Detlefsen, and P. E. Sørensen, "Offshore wind power data: Deliverable no: 16.1," Tech. Rep., 2012.

[24] K. Das, "Integration of renewable generation in power system defence plans," Ph.D. dissertation, Technical Universuty of Denmark, 2016.

[25] ENTSO-E, "Scenario Outlook \& Adequacy Forecast (SO\&AF) 2014-2030." [Online]. Available: https://www.entsoe.eu/publications/system-development-reports/adequacyforecasts/Pages/default.aspx

[26] ENTSO-E, "Supporting Document for the Network Code on Load-Frequency Control and Reserves." [Online]. Available: http://networkcodes.entsoe.eu/wp-content/uploads/2013/08/ 130628-NC_LFCR-Supporting_Document-Issue1.pdf 
This article has been accepted for publication in a future issue of this journal, but has not been fully edited.

Content may change prior to final publication in an issue of the journal. To cite the paper please use the doi provided on the Digital Library page.

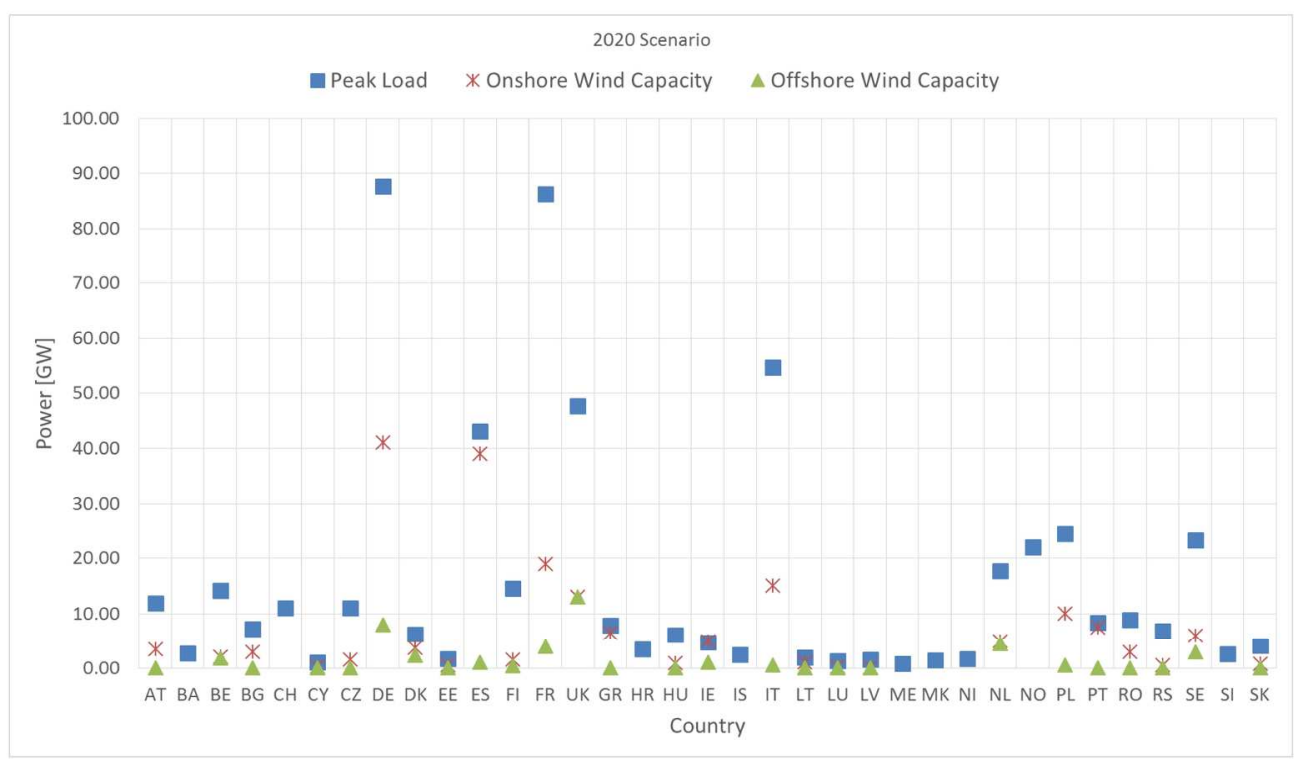

$186 \times 108 \mathrm{~mm}(300 \times 300 \mathrm{DPI})$ 
This article has been accepted for publication in a future issue of this journal, but has not been fully edited.

Content may change prior to final publication in an issue of the journal. To cite the paper please use the doi provided on the Digital Library page.

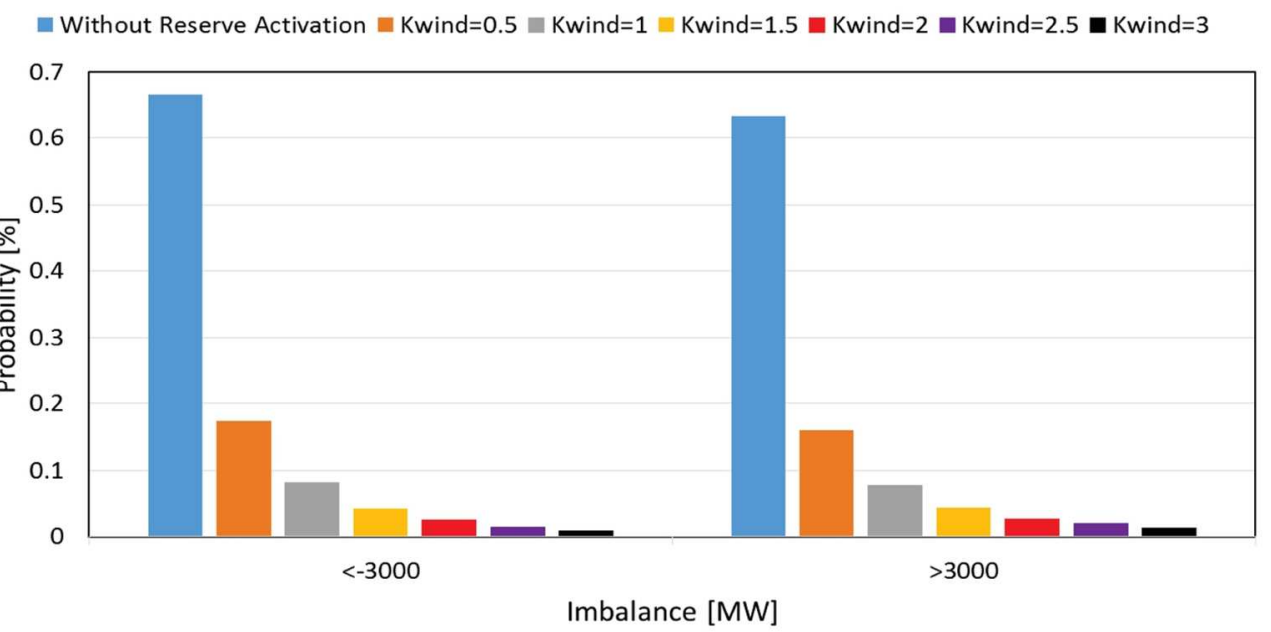

$117 \times 57 \mathrm{~mm}(300 \times 300 \mathrm{DPI})$ 
This article has been accepted for publication in a future issue of this journal, but has not been fully edited.

Content may change prior to final publication in an issue of the journal. To cite the paper please use the doi provided on the Digital Library page.

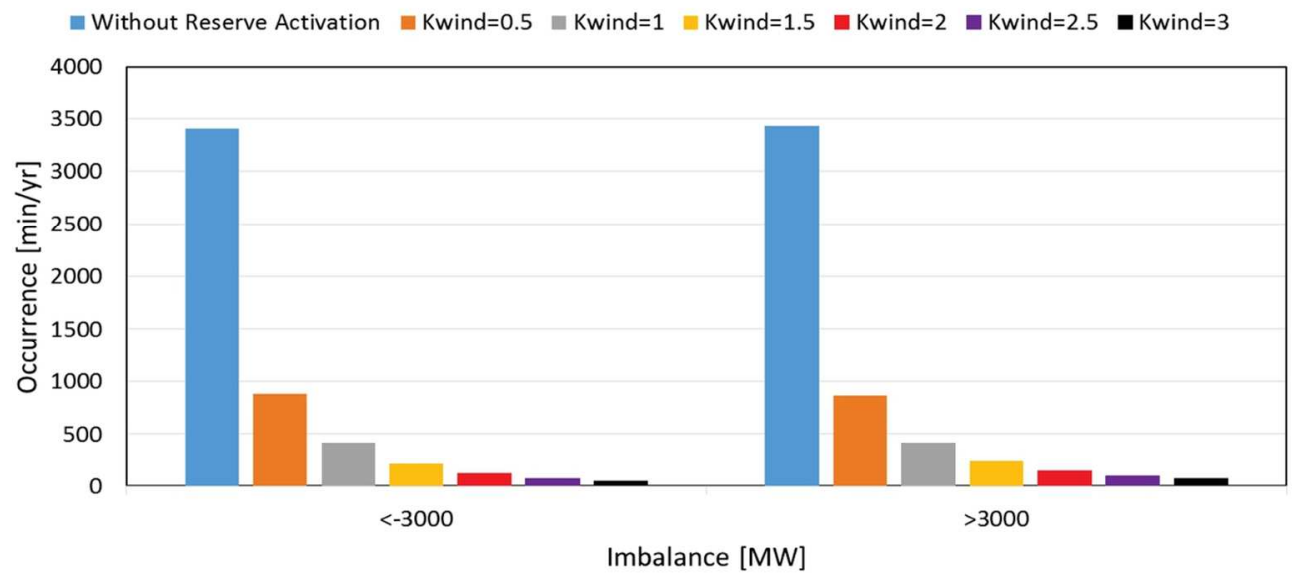

$111 \times 49 \mathrm{~mm}(300 \times 300 \mathrm{DPI})$ 
This article has been accepted for publication in a future issue of this journal, but has not been fully edited.

Content may change prior to final publication in an issue of the journal. To cite the paper please use the doi provided on the Digital Library page.

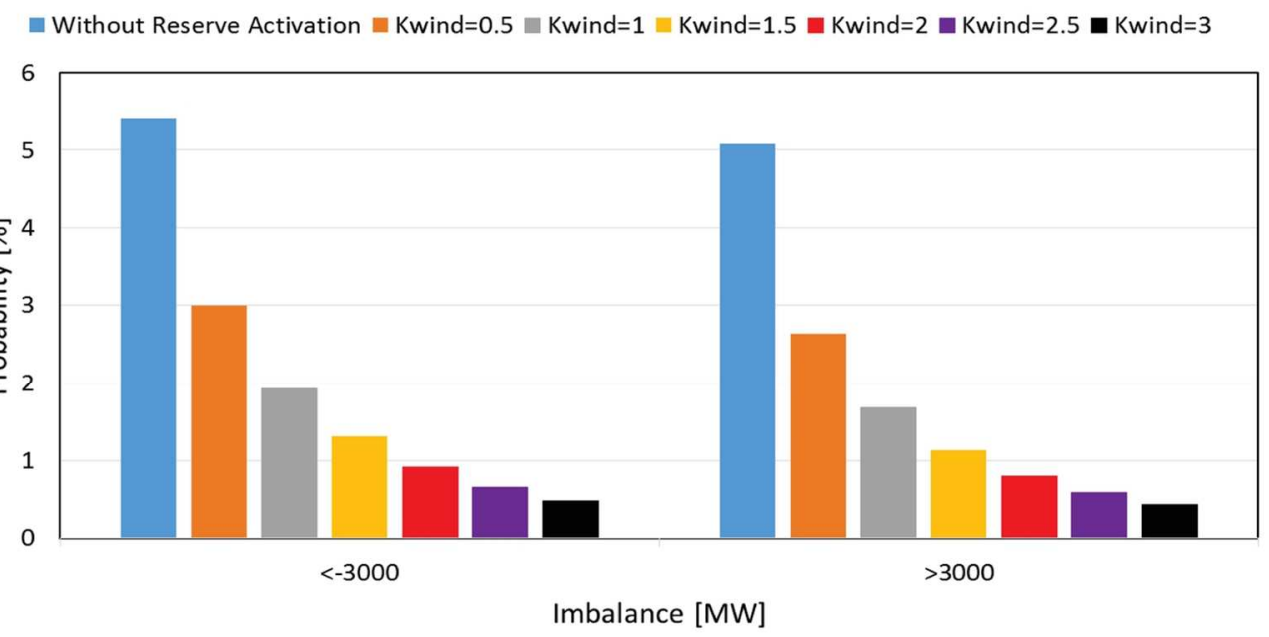

$117 \times 57 \mathrm{~mm}(300 \times 300 \mathrm{DPI})$ 
This article has been accepted for publication in a future issue of this journal, but has not been fully edited.

Content may change prior to final publication in an issue of the journal. To cite the paper please use the doi provided on the Digital Library page.

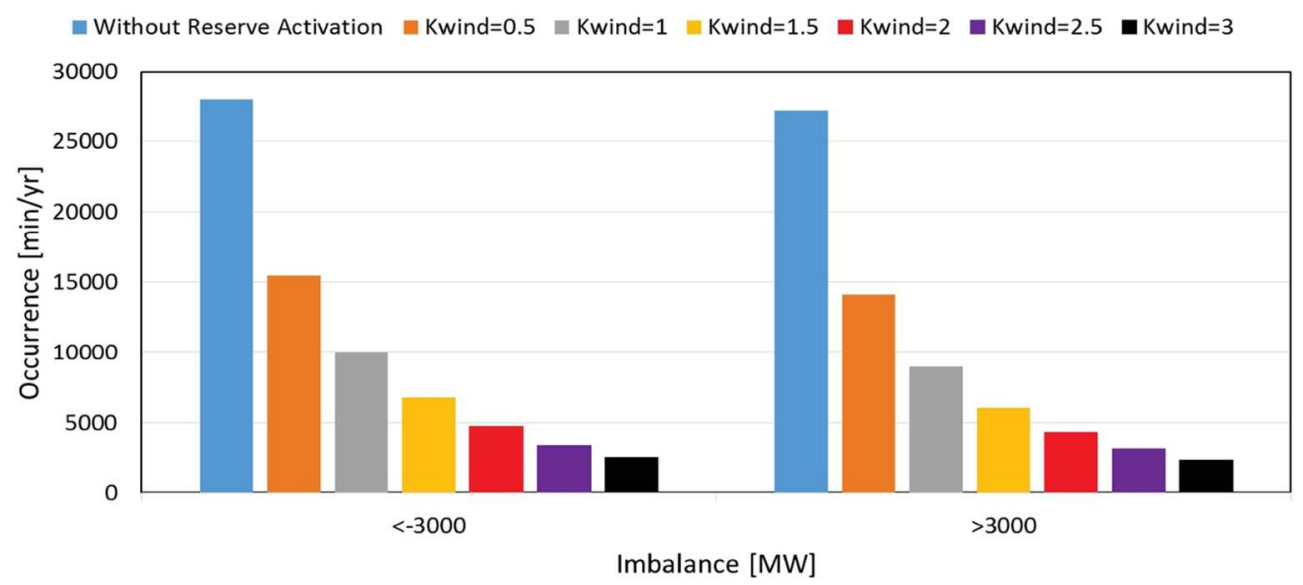

$111 \times 49 \mathrm{~mm}(300 \times 300 \mathrm{DPI})$ 
This article has been accepted for publication in a future issue of this journal, but has not been fully edited.

Content may change prior to final publication in an issue of the journal. To cite the paper please use the doi provided on the Digital Library page.

Installed Capacity of Wind Power Generation in GW

\begin{tabular}{ccccc}
\hline \multirow{2}{*}{ Network } & \multicolumn{2}{c}{2020} & \multicolumn{2}{c}{2030} \\
& Onshore & Offshore & Onshore & Offshore \\
\hline UK & 12.5 & 9 & 19 & 32 \\
CE & 166 & 25 & 217 & 94 \\
Baltic & 0.5 & 0 & 0.5 & 5 \\
Nordic & 8 & 9 & 10 & 28 \\
Ireland & 2 & 2.5 & 1.5 & 3 \\
\hline Total & 189 & 46 & 248 & 162 \\
\hline
\end{tabular}

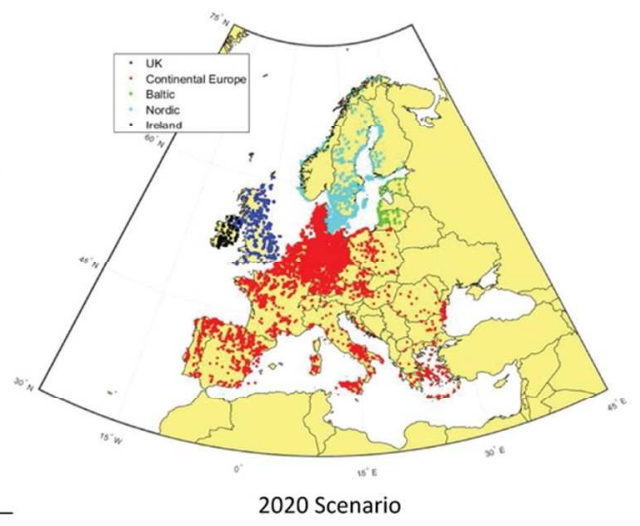

$92 \times 38 \mathrm{~mm}(300 \times 300 \mathrm{DPI})$ 
This article has been accepted for publication in a future issue of this journal, but has not been fully edited.

Content may change prior to final publication in an issue of the journal. To cite the paper please use the doi provided on the Digital Library page.

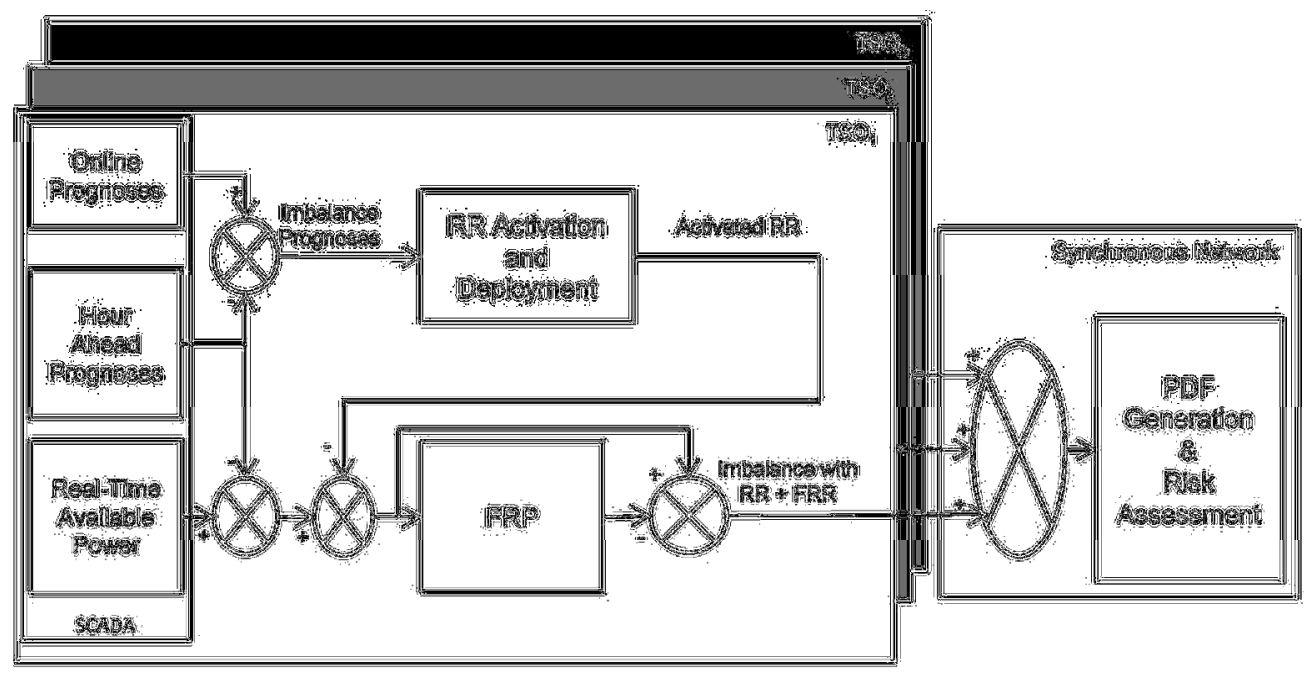

$88 \times 45 \mathrm{~mm}(300 \times 300$ DPI $)$ 
This article has been accepted for publication in a future issue of this journal, but has not been fully edited.

Content may change prior to final publication in an issue of the journal. To cite the paper please use the doi provided on the Digital Library page.

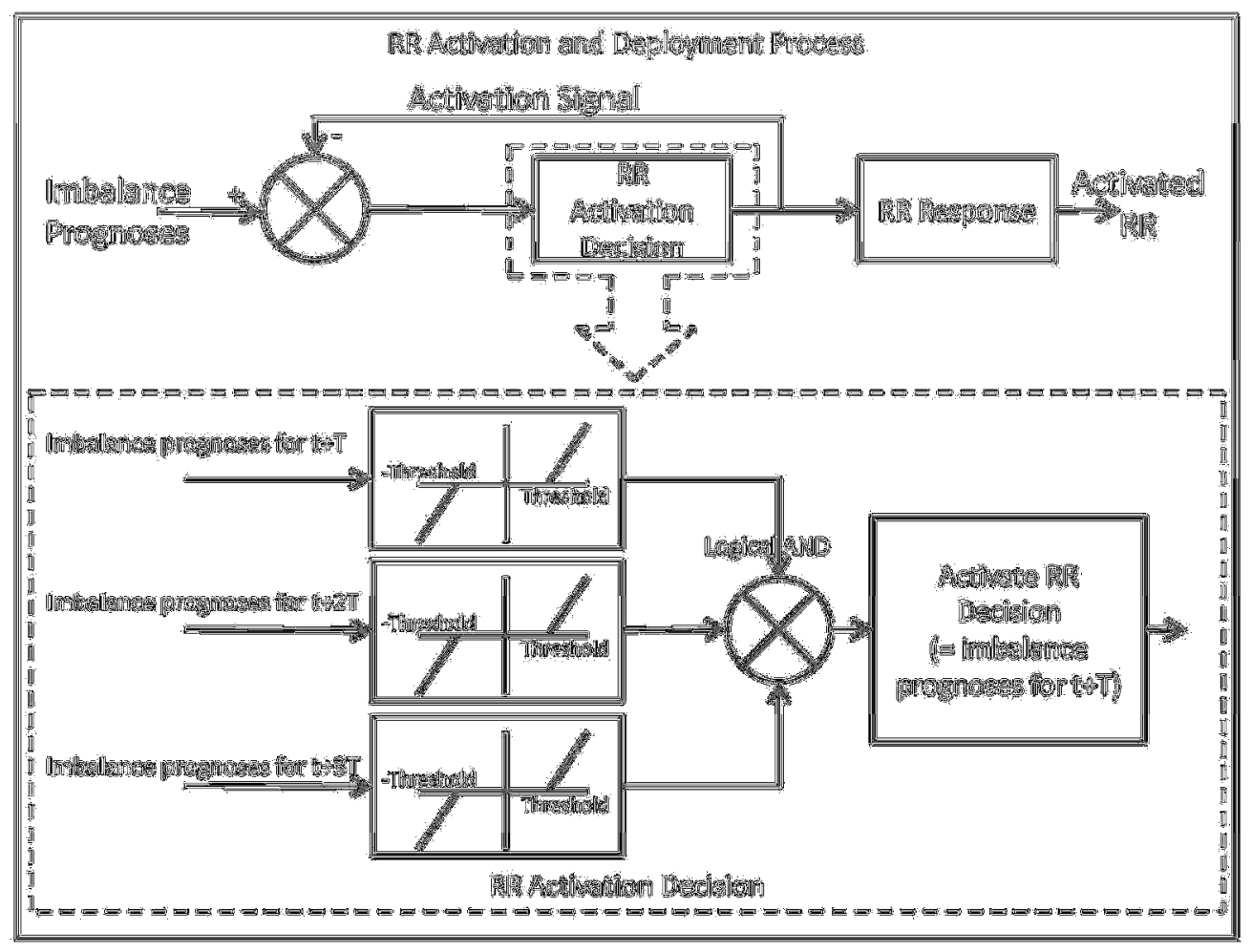

$153 \times 116 \mathrm{~mm}(300 \times 300 \mathrm{DPI})$ 
This article has been accepted for publication in a future issue of this journal, but has not been fully edited.

Content may change prior to final publication in an issue of the journal. To cite the paper please use the doi provided on the Digital Library page.

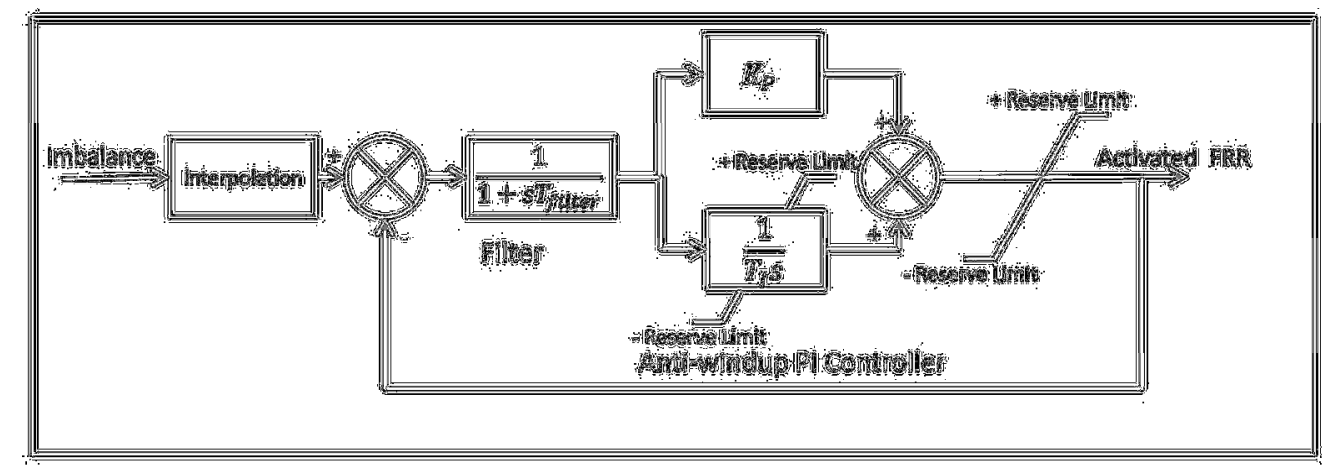

$86 \times 30 \mathrm{~mm}(300 \times 300$ DPI $)$ 
This article has been accepted for publication in a future issue of this journal, but has not been fully edited.

Content may change prior to final publication in an issue of the journal. To cite the paper please use the doi provided on the Digital Library page.

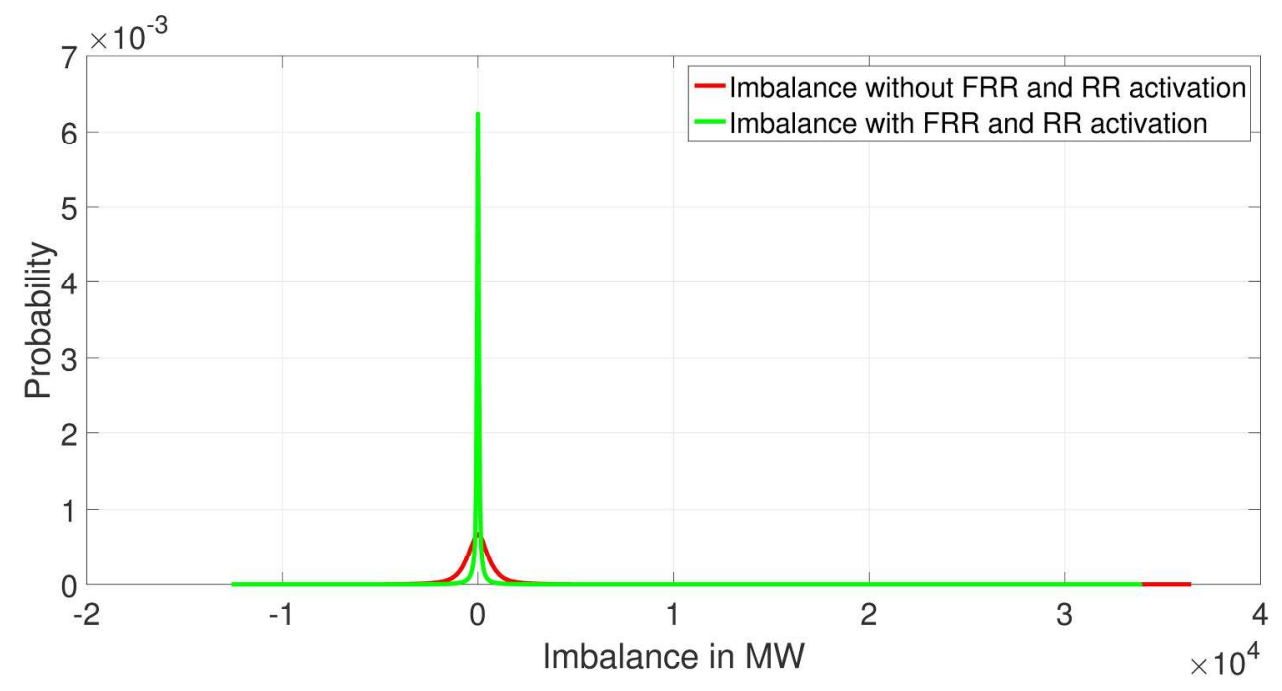

$234 \times 123 \mathrm{~mm}(300 \times 300 \mathrm{DPI})$ 
This article has been accepted for publication in a future issue of this journal, but has not been fully edited.

Content may change prior to final publication in an issue of the journal. To cite the paper please use the doi provided on the Digital Library page.

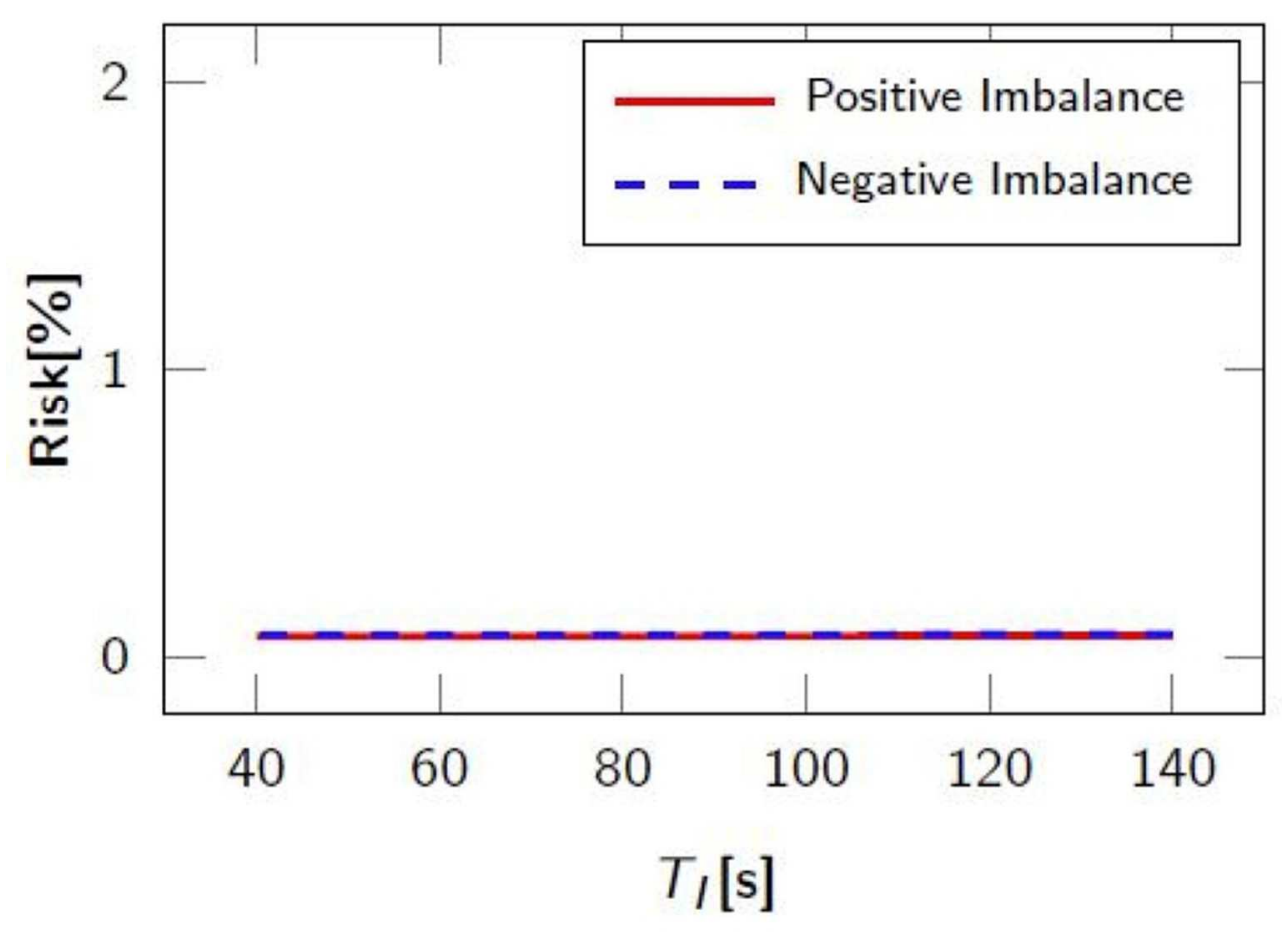

$72 \times 51 \mathrm{~mm}(300 \times 300$ DPI $)$ 
This article has been accepted for publication in a future issue of this journal, but has not been fully edited.

Content may change prior to final publication in an issue of the journal. To cite the paper please use the doi provided on the Digital Library page.

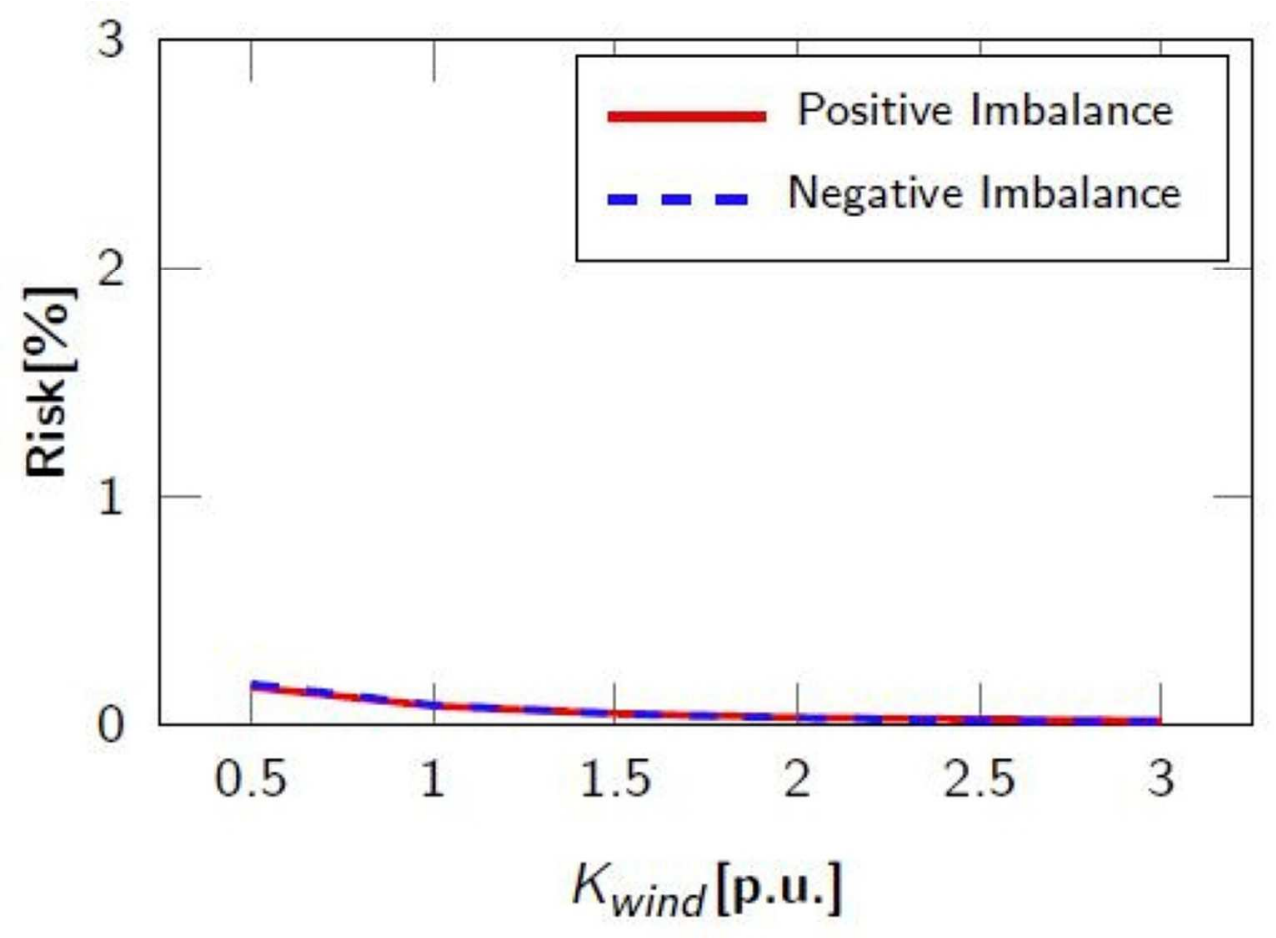

$74 \times 53 \mathrm{~mm}(300 \times 300 \mathrm{DPI})$ 
This article has been accepted for publication in a future issue of this journal, but has not been fully edited.

Content may change prior to final publication in an issue of the journal. To cite the paper please use the doi provided on the Digital Library page.

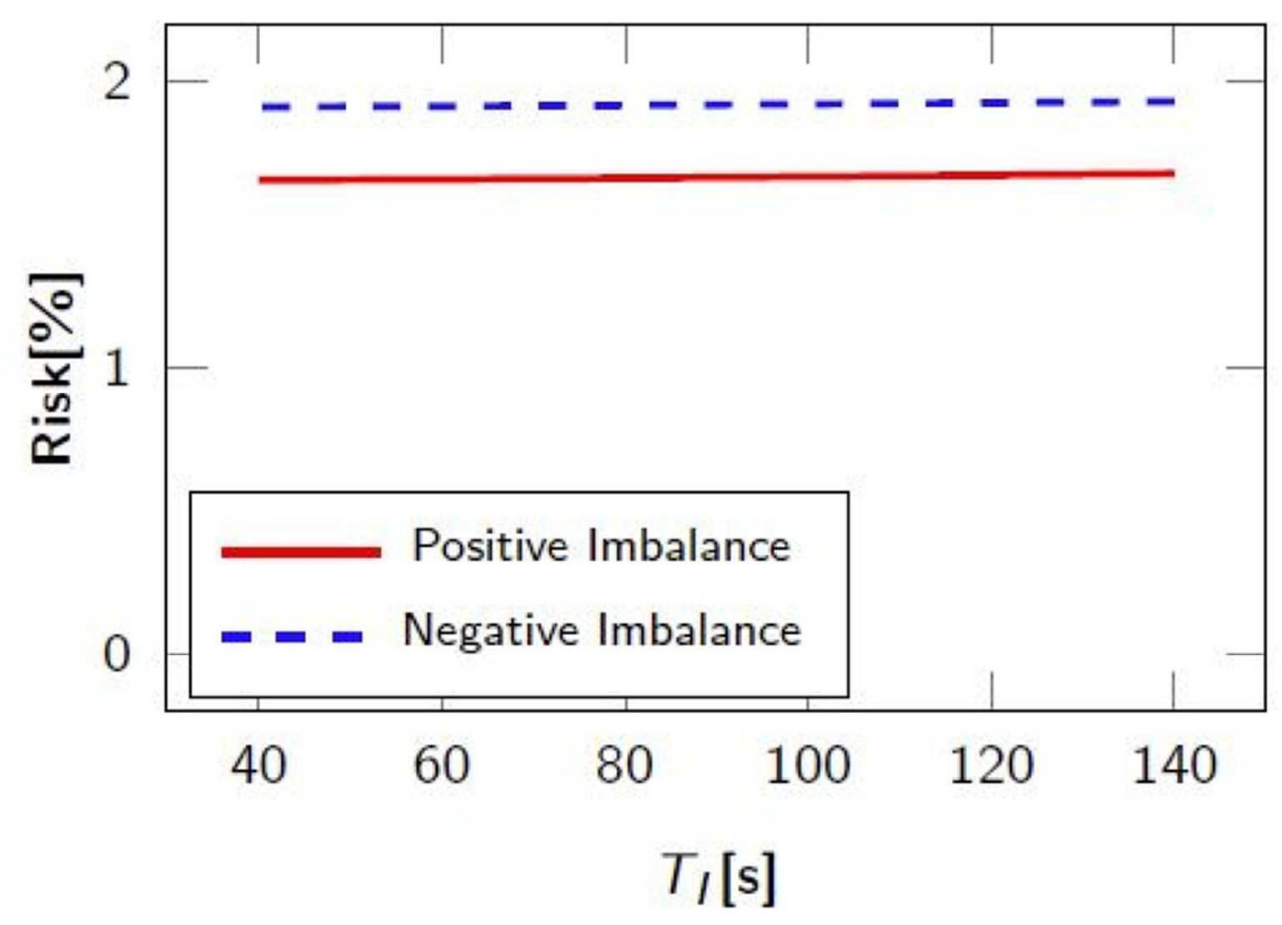

$71 \times 50 \mathrm{~mm}(300 \times 300$ DPI $)$ 
This article has been accepted for publication in a future issue of this journal, but has not been fully edited.

Content may change prior to final publication in an issue of the journal. To cite the paper please use the doi provided on the Digital Library page.

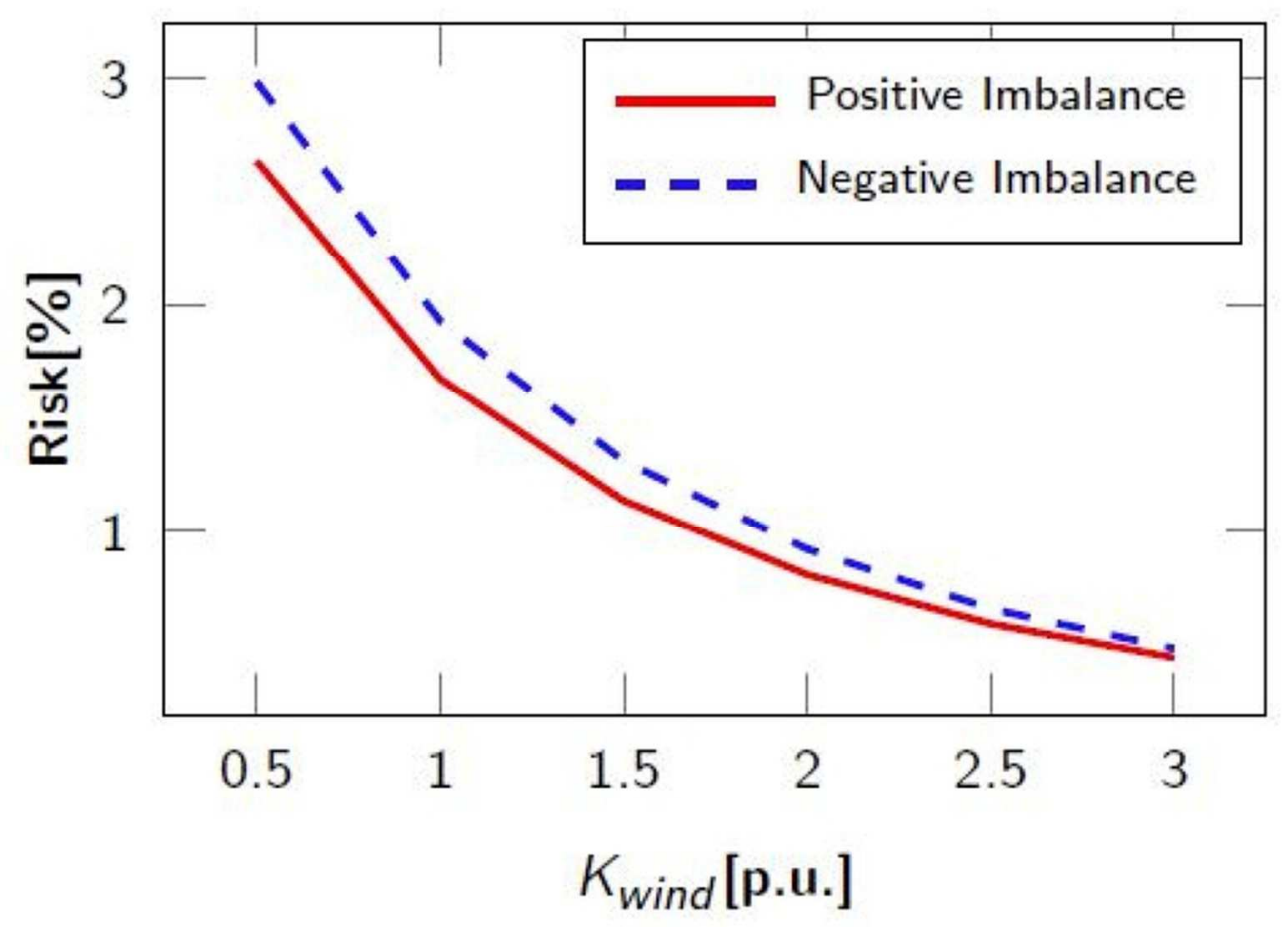

$73 \times 53 \mathrm{~mm}(300 \times 300$ DPI $)$ 